




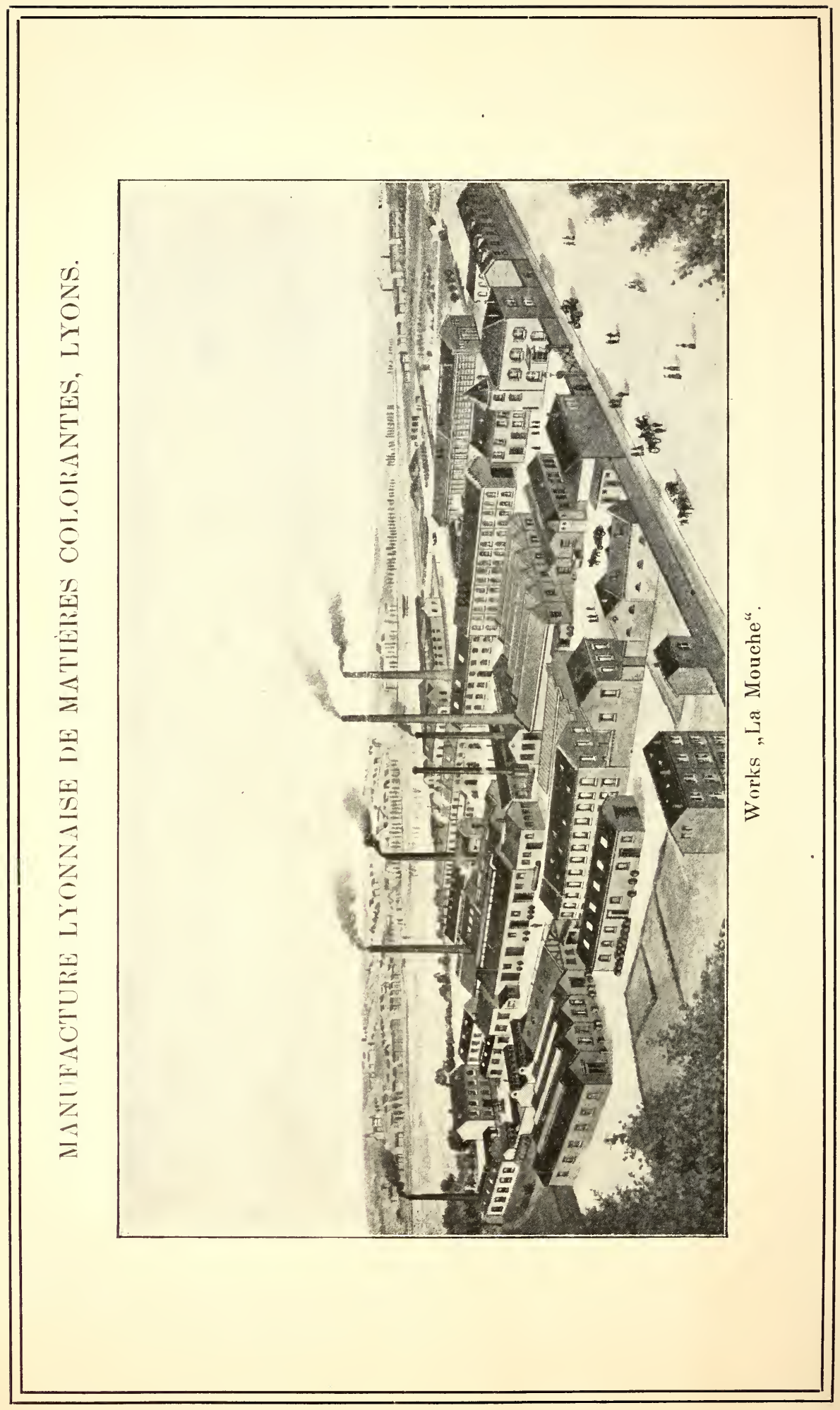




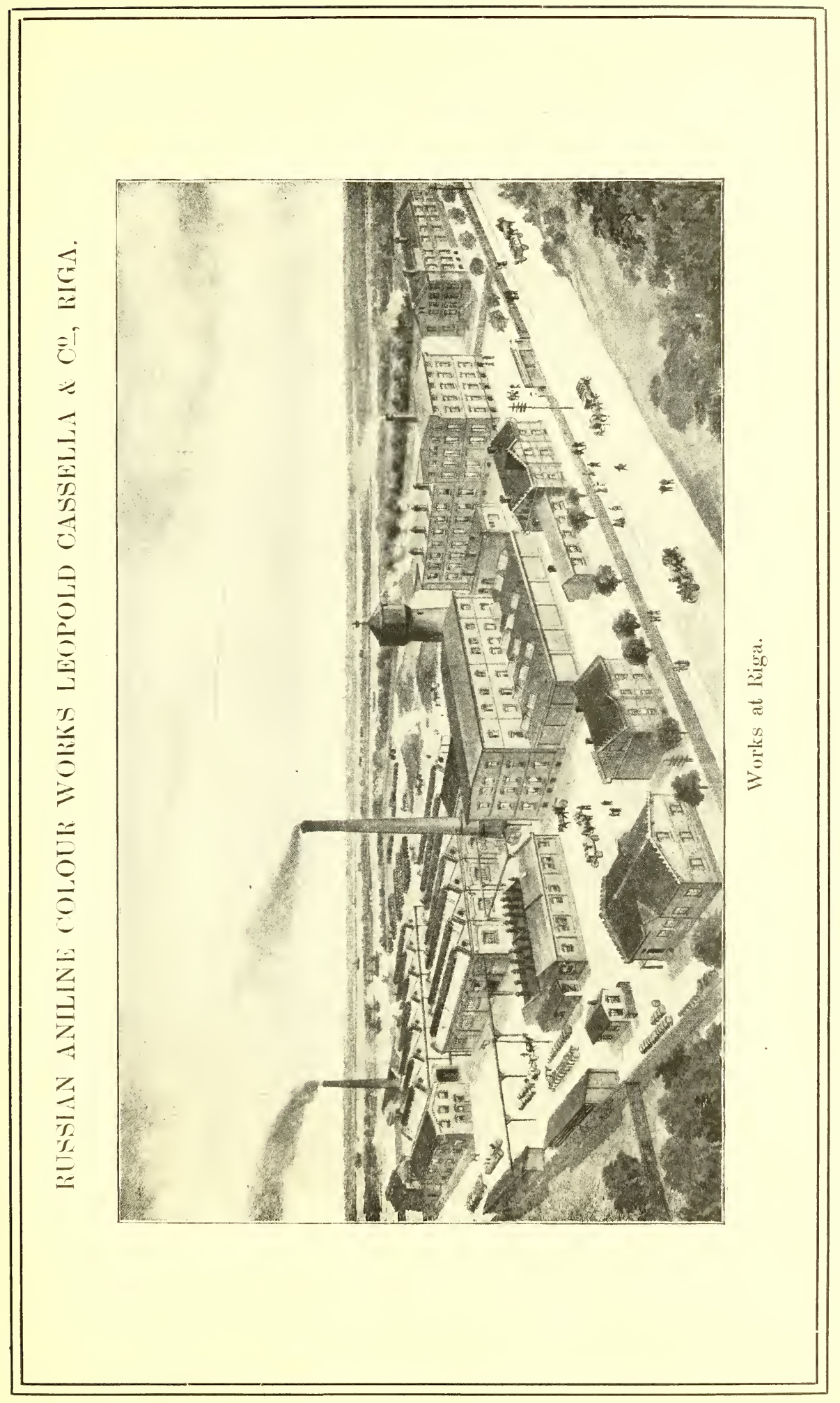




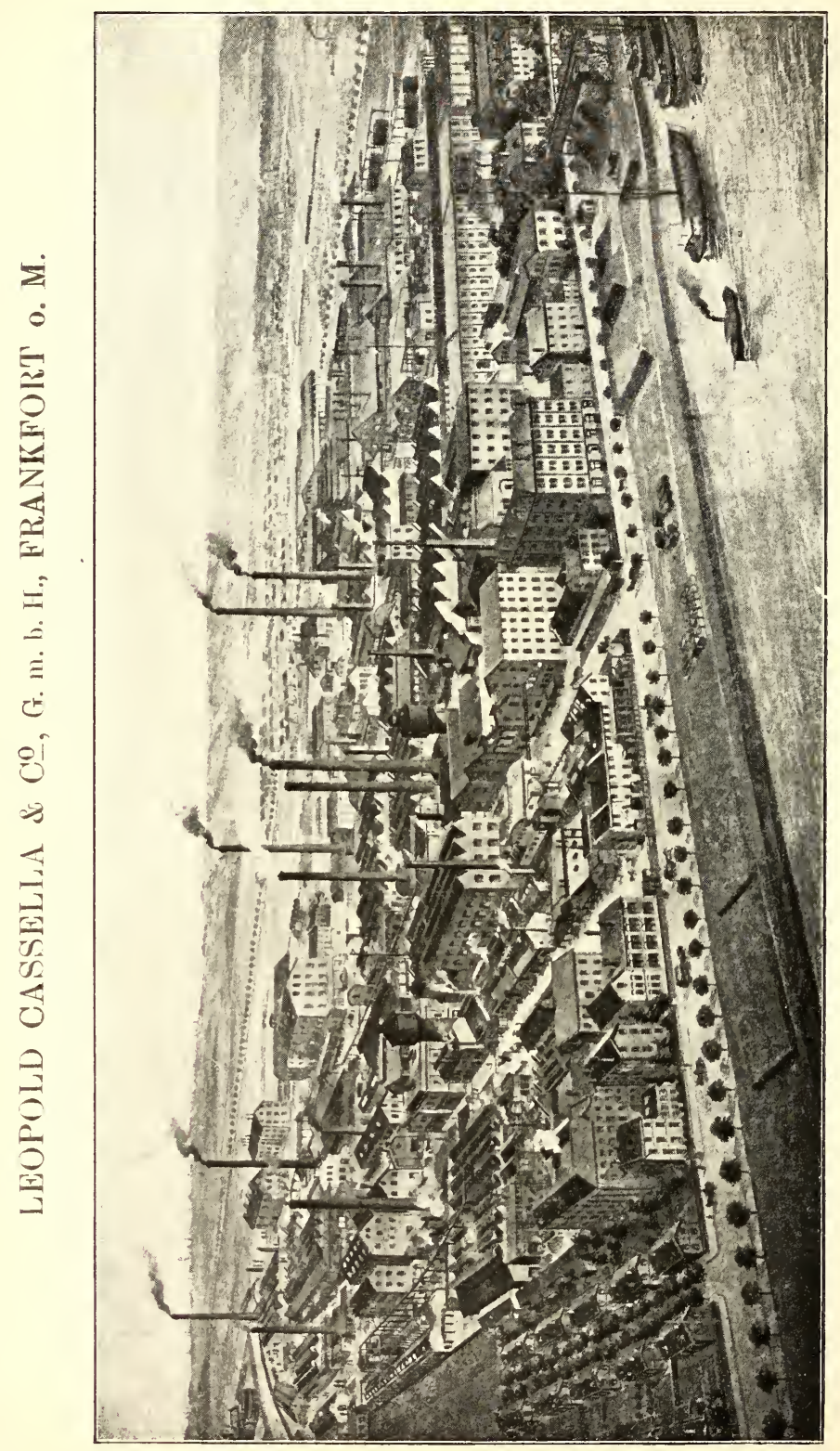

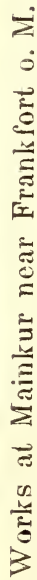




\title{
THE DYEING OF LEATHER
}

\author{
WITH THE
}

\section{DYESTUFFS}

OF

\section{CASSELLA COLOR COMPANY}

(AMERICAN BRANCH of LEOPOLD CASSELLA \& C으, a. m. b. н.)

182 AND 184 FRONT STREET

\section{NEW YORK}

BOSTON : 68 ESSEX STREET

PHILADELPHIA: 126 AND 128 SOUTH FRONT STREET

PROVIDENCE: 64 EXChange PLACE

ATLANTA: 47 NORTH PRYOR STREET MONTREAL, CANADA, 59 WILliam STREETí
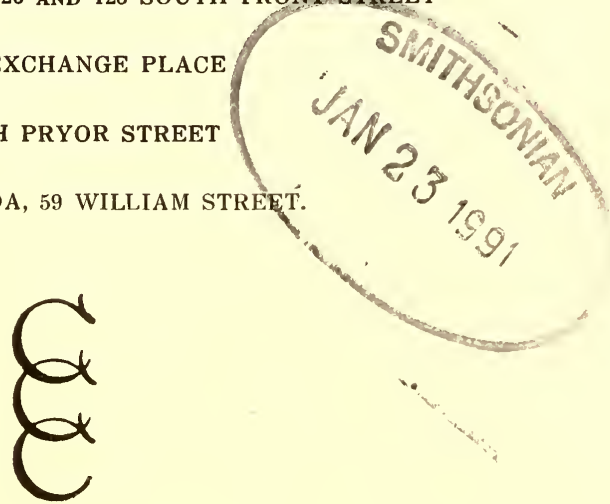



\section{CON'TENTS.}

PAGE

Dissolving the Dyestuffs

1

I. Bark-tanned and Sumac-tanned Leather . . . . . . 3

Preparatory Treatment of the Leather. . . . . . . . . 5

Application of the Dyestuffs . . . . . . . . . . . 5

Methods of Inyeing . . . . . . . . . . . . s

Special Dyeing Directions . . . . . . . . . . 10

II. Chrome Leather . . . . . . . . . . . . 13

Preparation of the Leather . . . . . . . . . . . . 15

Neutralising Chrome Leather . . . . . . . . . . . 16

Directions for Dyeing and Applying the Dyestuffs . . . 16

1. Acid Colours on Chrome Leather . . . . . 16

2. Basic Colours on Chrome Leather . . . . 18

3. Dyeing by the Combination Method . . . . 19

4. Black on Chrome Leather. . . . . . . . . 20

III. Chamois Leather . . . . . . . . . . . . . 23

Preparation of the Leather . . . . . . . . . . . . . 25

Dyestuffs to be employed . . . . . . . . . . . . 25

Application of the Dyestuffs . . . . . . . . . . . . 26 


\section{Remarks in connection with the Tables of Patterns.}

The patterns marked with an asterisk $\left(^{*}\right)$ are produced with Basic Colours, those marked with a cross $(\dagger)$ with Acid Colours, whilst those marked $\S$ are dyed according to the method indicated on page 10 for grey and beige shades with the addition of $10 \mathrm{oz}$ soap per 5 doz. skins.

Table

I and II. Bark-tanned Cowhides. Patterns Nos. 1-20 are produced by staining the moist leather and represent shades suitable for harnesses, the making of bags, and upholstery.

III and IV. Bark-tanned Goatskins. Patterns Nos. 21-36 are produced in the tray and represent the favourite mode shades in boot and shoe manufacture.

V. Bark-tanned Calfskins. Patterns Nos. 37-46 are dyed in the tray and represent shades for boot and shoe manufacture.

VI-VIII. Sumac-tanned Calfskins. Patterns Nos. $47-74$ are produced in the tray, Nos. 75 and 76 by staining. These are mode and fancy shades for fancy goods (pocket-books, purses, etc.)

IX-XII. Sumac-tanned Sheepskins. Patterns Nos. 77-116 are produced in the tray. The shades are in demand for leather for book binding, fancy goods and upholstery.

XIII and XVII. Sumac-tanned Skivers. Patterns Nos. 117-164 are dyed in the tray Nos. $165-167$ produced by staining. Some of them are useful for hat leather and others for lining and book binding purposes.

XVIII. Chrome-tanned Calfskins. $\mid \begin{aligned} & \text { Dyed according to the special } \\ & \text { instructions given for chrome }\end{aligned}$ XIX. Chrome-tanned Goatskins. $\begin{aligned} & \text { leather. These kinds of leather are } \\ & \text { used for boot and shoe nanufacture. }\end{aligned}$

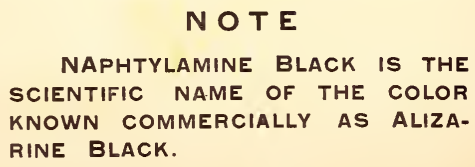




\section{Dissolving the Dyestuffs.}

The dyestuffs are best dissolved in tin-plated, enamelled or earthen vessels. Wooden vessels should be avoided, especially if it be of importance to maintain the same concentration of the dyestuff solutions, besides which wooden vessels are rather difficult to clean, so that they should only be employed for dissolving dyestuffs of the same or of similar shades.

a) Basic Colours are best dissolved in condensed or very soft water (rain water); if such be not available, ordinary river or well water may of course be used, which must however be corrected first by adding acetic or formic acid. The quantity of the acid to be used may be ascertained from the following tabulation.

100 gallons water of a hardness of 10 English degrees (being equal to 8 German degrees or 14,3 French degrees) require for correction about

$$
\begin{aligned}
& 91 / 4 \text { oz acetic acid of } 30 \% \text {, being equal to } 8 \mathrm{deg} \text {. Tw., or } \\
& 51 / 2, \quad, \quad, 50 \%, \quad, \quad, \quad \text { " } 12 \text { deg. Tw., or } \\
& 3.4 \quad, \quad, \quad, 80 \%, \quad, \quad, \quad, 15 \text { deg. Tw. }
\end{aligned}
$$

$81 / 2$ oz formic acid of $25^{\circ} / 0$, being equal to $12 \mathrm{deg}$. Tw., or

$41 / 4, \quad, \quad, 500^{\circ}, \quad, \quad, \quad, 24$ deg. Tw., or

$21 / 2 \quad, \quad, \quad, 80 \%, \quad, \quad, \quad$, 36 deg. Tw.

An exception are the Diamond Phosphines, which otherwise behave like all the other Basic Colours, but which, owing to their indifference towards lime (calcareous water), may be dissolved in all cases without the addition of acetic acid.

The dyestuffs are mixed to an even paste with some cold water and the requisite quantity of acid; if necessary boiling water is then poured over the paste, and after some stirring the dyestuff will be completely dissolved.

b) Acid Colours are dissolved in the same manner, but without the addition of acid.

These dyestuffs are generally dyed with the addition of sulphuric or formic acid. It is not, however, advisable to add the acid to the stock solution, such addition being apt to affect the solubility of certain 
Acid Colours and to make them partly precipitate. This addition is therefore best made immediately before dyeing.

It is recommended to dissolve just as much dyestuff as may be required for one or two days, because the concentration of the solution is apt to change in summer by evaporation, and in winter by the precipitation of some dyestuff through freezing. 
I.

BARK-TANNED AND SUMAC-TANNED LEATHER. 



\section{Preparatory Treatment of the Leather.}

This comprises the following manipulations:

1. Careful cleansing of the leather from all unfixed tanning material still adhering by means of thorough drumming or kneading. This includes of course a thorough softening of the leather in case it has been dried previously.

2. Replacing the tannin thus lost by sumac or some other tanning agent favourably affecting the dyeing operation.

3. Mechanical treatment of the leather in order to render the grain smooth and pliant.

4. Sumac-tanned leather, which is not to be dyed immediately, is dried on frames and stored in a dry place, but must before dyeing be soaked well; it is however the general custom to dye the freshly prepared leather straightaway. Bark-tanned leather, after having undergone the above preparatory treatment, is frequently softened slightly with oil. Before dyeing it is then drummed thoroughly.

\section{Application of the Dyestuffs.}

a) Basic Colours become fixed directly by the tanning material of the leather and therefore call for no additions to the dyebath. The various tanning materials serving for the tanning of the leather are not however all equally well suited for fixing Basic Colours; thus it is necessary to subject bark-tanned leather to a re-tannage with sumac, this tanning material having proved best suited as a bottoming for dyeing. This extra tannage at the same time brings about quite a considerable brightening of the leather which by the tanning with bark has assumed a more or less deep shade. - For sumac-tanned leather, such re-tannage is unnecessary, provided that the dyeing takes place immediately, or at least not long after the tanning process. The longer however the time between the tanning and the dyeing process, the more does the tanning matter fixed on the leather lose the property to uniformly fix the dyestuff; in such a case it is advantageous to resort to a re-tannage with some sumac.

b) Acid Colours may be dyed on any kind of leather without previous mordanting, but in order to use them to full advantage, they 
should be dyed with an addition of sulphuric or formic acid. As a rule 1 part by weight of concentrated sulphuric acid or 2 parts by weight of formic acid of $50 \%$ are employed for every 4 parts by weight of dyestuff. The acid is added in a highly diluted form, say, in a $1 \%$ solution.

Whether Basic or Acid Colours are to be used depends on the shades required, as also on the method of dyeing to be followed. Mode shades, such as havana, etc., may be dyed with Basic or with Acid Colours; especially bright and brilliant fancy shades (such as crimson, cochineal, pale blue, pale green, etc.) are as a rule produced to better advantage with Acid Colours, deep shades on the other hand, such as chocolate, are to more advantage produced with Basic Colours. The patterns shown in this book will in this respect offer more details. - Regarding the method of dyeing to be followed, it should be borne in mind that in all instances where the dyeing is done in a bath (in a tray, paddle or drum) and where there are facilities afforded for washing or rinsing the leather after dyeing, the Acid Colours are applicable in the same manner as the Basic Colours, by reason of the fact that any excess of acid can be neutralised, or at least partly so, by the subsequent washing operation. If, however, it is not feasible to wash, as for instance when dyeing by the staining process, Acid Colours should only be recommended if the fixing is to be carried out with formic acid, especially where high demands are made witl regard to the durability of the leather. Formic acid evaporates during the drying of the leather, sulphuric acid on the other hand remaining permanently in the leather.

If the goods are required to be fast to rubbing, the Acid Colours should in all cases be given the preference, although Basic Colours may also come into consideration for leather which during the dressing is provided with a finish that improves the resistance to rubbing.

In point of fastness to light there is little difference between the Basic and Acid Colour's enumerated below, this tabulation only containing dyestuffs which are amongst the fastest available for the respective shades.

Fastness to alkalies as a rule comes into consideration only in the case of leather which is to be used for the manufacture of shoes and boots, for which purpose the Diamond Phosphines, which principally serve for producing most mode shades, answer every requirement.

The following products serve principally for dyeing the various kinds of bark-tanned and sumac-tanned leather:

Basic Colours:

Yellow:

Thioflavine TCN

Thioflavine $\mathrm{T}$

Diamond Phosphine GG

Orange:
Tannin Orange $\mathrm{R}$

Diamond Phosphine R.
Acid Colours:

Naphtol Yellow S

Milling Yellow O

Orange II, R, extra, ENZ 


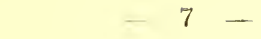

Basic Colours:

Acid Colours:

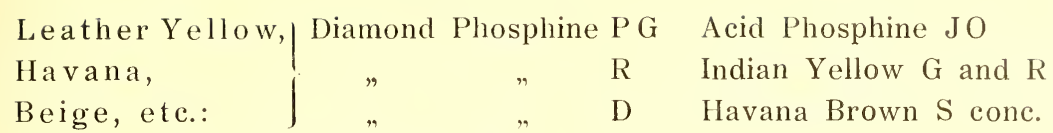

Phosphine II.

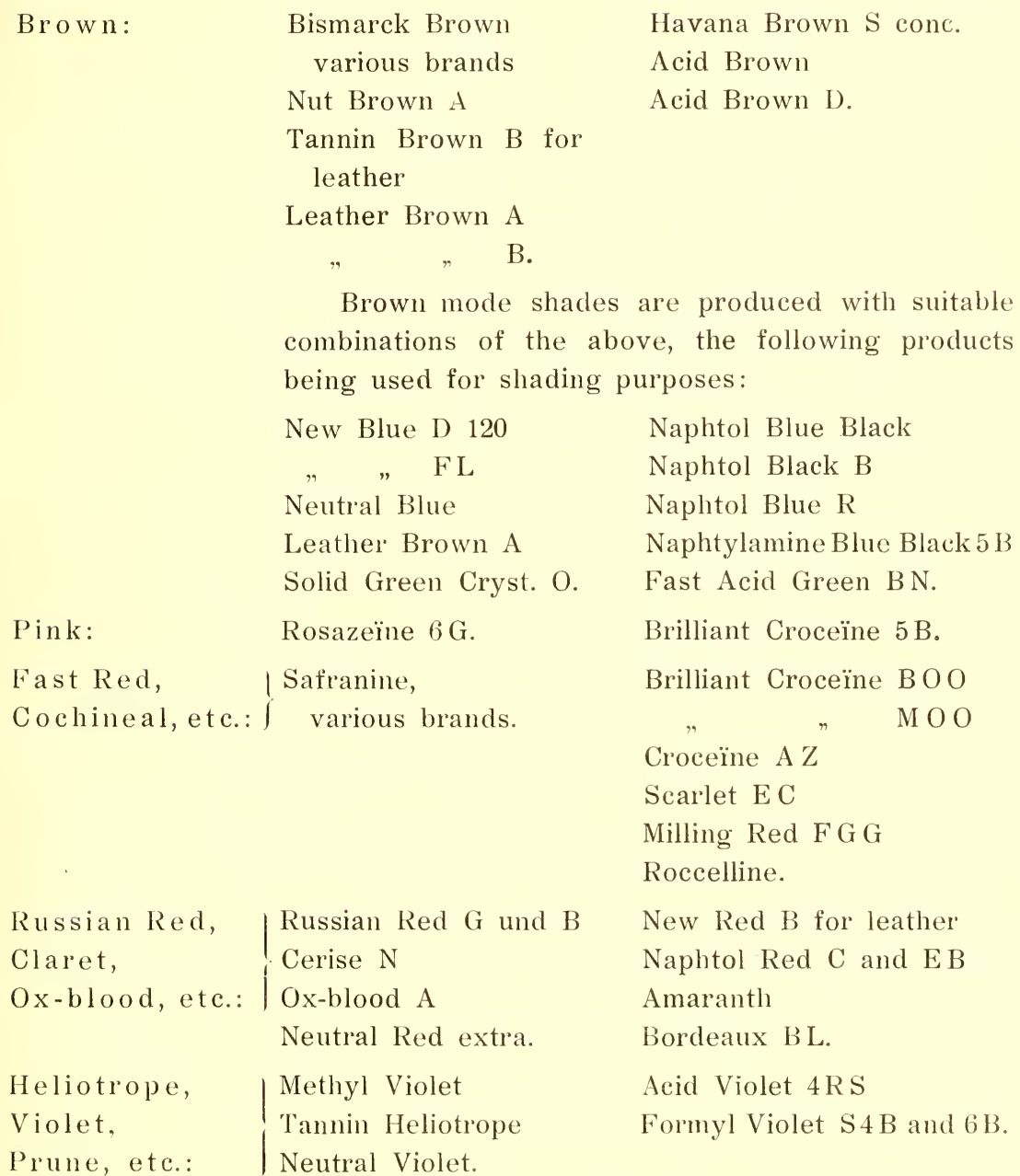

Blue and red dyestuffs are used for shading, brown dyestuffs for saddening purposes.

Blue:

Methylene Blue DBB Solid Blue $R$ and $6 \mathrm{G}$

New Methylene Blue N,GG Naphtol Blue R and G and other brands Pure Soluble Blue

New Blue D 120 and FL Water Blue B

Neutral Blue.

Cyanole, various brands

Formyl Blue B. 


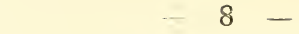

Basic Colours:

Acid Colours:

Green: $\quad$ Solid Green Crystals O Malachite Green conc.

Acid Green extra conc. and $5 \mathrm{G}$

Brilliant Green Cryst. extra.

Fast Acid Green B N

Cyanole Green B

Naphtol Green B.

Olive: produced with

Diamond Phosphine G G, Indian Yellow $\mathrm{G}$ or $\mathrm{R}$ $\mathrm{P} G$ or $\mathrm{R}$

and New Blue F L, D 120

or

Methylene Blue DBB.

Grey:

B la ck:

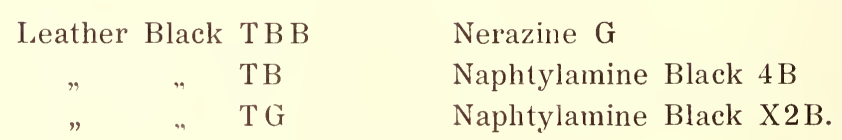

and Cyanole extra,

Naphtol Blue $\mathrm{R}$ or

Naphtol Green B.

Neutral Black B for leather

Nerazine G.

Blue, red, orange and brown dyestuffs are used for shading.

Any of the Basic Colours may be used in combination with one another, likewise the Acid Colours, but Basic and Acid Colours, or their solutions, must not be mixed together. If for a certain shade both Basic and Acid Colours are required, the goods should be dyed with the Acid Colour first and be topped afterwards with the Basic Colour.

\section{Methods of Dyeing.}

1. Staining is resorted to for large heavy hides (cow hides) which cannot be moved about freely in a dye-vessel, and generally also for all kinds of leather the flesh-side of which is to remain perfectly unstained, and where the flesh can either be only very slightly fluffed or not at all.

In dyeing the leather in the dry state, it is first given a coating of a dilute dyestuff solution, to preclude as far as possible the dyeing turning out uneven; the stronger solution is only applied when the first has been fully absorbed by the leather.

If the leather is to be dyed in a damp state, a strong dyestuff solution may be brushed on straightaway without any risk of unlevel results.

When dyeing the leather damp, the dyestuff solution should not be any stronger than $1 \mathrm{lb}$ dyestuff per 10 gallons water, and in the case of dry leather, the quantity of dyestuff should not exceed $8 \mathrm{oz}$ per 
10 gallons. If more concentrated solutions be used, the dyeings of certain dyestuffs cannot be prevented from assuming a bronzy gloss.

If the afore-mentioned concentrations should not prove sufficient for particularly full and deep shades, it is preferable to repeat the staining several times.

Basic Colours, when dissolved as stated on page 1, are applied without any further addition.

Acid Colours are dyed with the addition of 1 part by weight of formic acid of $50 \%$ for every 2 parts by weight of dyestuff. An addition of sulphuric acid is not to be recommended when working according to the staining process (see page 6).

The temperature of the dyestuff solution should be higher than $35^{\circ}$ C. (95 deg. F.), but should not exceed $60^{\prime \prime}$ C. (140 deg. F.).

2. The dyeing in the bath may be carried out:

a) In the tray. 1 to 2 dozen skins are dyed in one lot. The skins are folded along the back, the flesh-side inside, and then drawn alternately through the dye-liquor. The quantity of dye-liquor should be sufficient to handle the skins easily. The dyeing lasts 15 to 20 minutes. The temperature of the bath should be $35-45^{\circ}$ C. (95-115 deg. F.). For a dozen medium-sized skins, up to $4 \mathrm{oz}$ of Basic Dyestuff or 5 oz of Acid Dyestuff are used.

In some districts the dyeing is carried out in small trays, 2 skins only being dyed at a time which are paired together flesh to flesh. In this case about $1 \frac{1}{1 / 2}$ gallons of liquor and up to $3 / 4$ oz of Basic Dyestuff or $1 \mathrm{oz}$ of Acid Dyestuff are used, the dyeing requiring about ten minutes.

b) In the paddle or in the drum. The skins are first of all treated with warm water in order to give them the right temperature. The dyestuff solution is then added to the dye-vessel, in which the skins are dyed for about 20 to 30 minutes. It is best to keep the temperature of the liquor between 50 and $55^{\circ}$ C. (120 to $130 \mathrm{deg}$. F.), the volume of liquor being regulated by the size of the vessel and the number of skins to be

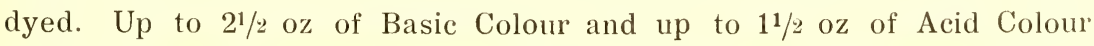
are the usual quantities allowed for a calf-, goat- or sheep-skin of medium size.

When dyeing in a bath, Basic Colours dissolved in accordance with the indications on page 1 of this volume are applied without any other addition whatever, but for Acid Colours it is necessary to add 1 part by weight of sulphuric acid or 2 parts by weight of formic acid of $50 \%$ for every 4 parts by weight of dyestuff. If sulphuric acid has been used and special requirements are made with regard to durability, it is recommended to wash the leather subsequently to the dyeing, either with plain water or better still with a weak solution of acetate or formate of soda. 
Calf-, goat- or sheep-skins are usually dyed in the tray if there is no objection to the border of the flesh-side being stained a hand's breadth, or if the thickness of the skin allows of such stained borders being removed by fluffing The paddle or drum is applied if the fleshside is desired to be dyed uniformly, similarly to the grain. Dyeing in the drum, besides being resorted to for the above named different kinds of leather, comes into consideration for the dyeing of neats bellies and necks, and sometimes even for whole cowhides.

\section{Special Dyeing Directions.}

Grey and Beige Shades. If the leather prepared in the ordinary way is still in a very acid condition from the tanning, it is first of all milled or kneaded for some time in a borax solution $(1 / 40 / 0)$. It is then dyed with the Acid Colours indicated below with the addition of a soap solution, either by staining or in the bath, the method of working being the same as usual. No acid should, however, be added, which would in fact have a detrimental effect in this case. For this purpose the following Acid Colours come mainly into consideration:

Grey:

Neutral Black B for leather

Nerazine G.

For shading: Orange extra Orange ENZ, Cyanole FF, Havana Brown S conc., ete.

Beige, Champagne Colour, Pea

Green, Straw Colour, etc.: Havana Brown S conc.

For shading: Neutral Black B for leather, Nerazine G, and the dyestuffs mentioned for Greys.

Leather with a buffed grain is dyed to best advantage with Acid Colour's. For fancy shades, only unstuffed leather or leather that has only been stuffed very slightly can be used. First of all the solution of an Acid Colour (41/2- $-\delta$ oz per 10 gallons according to requirement) is brushed on without any acid being added, or a weaker solution is applied in the bath. After drying the leather, another solution containing not more than $4^{1 / 2}$ oz dyestuff per 10 gallons water and $3-8$ oz formic acid is brushed on, which fixes the dyestuff.

If leather with a buffed grain is to be dyed black, it is first given a coating of Nerazine G (1 lb per 10 gallons) with the addition of $8 \mathrm{oz}$ 
formic acid of $50 \%$, and when dry another coating is given with Leather Black TB or T G ( $1 / 2-1 \mathrm{lb}$ per 10 gallons).

Strongly stuffed leather is only suitable for dyeing black; before dyeing, the side to be dyed is rubbed with a lukewarm solution of $1-2 \mathrm{lbs}$ borax per 10 gallons water until the fat attaching thereto is dissolved and the leather allows of being wetted easily. The leather is then blackened in the usual manner, as a rule by staining. 
II.

CHROME LEATHER. 



\section{Preparation of the Leather.}

During its manufacture and dressing, chrome leather is subjected to a good many more treatments of a mechanical character than barktanned leather. A sound grain is most essential for ensuring a good colour, and in selecting and treating the raw skins, the following points should therefore in the first place be carefully observed:

1. Only perfectly sound and clean-grained skins should be used for chrome-tannage.

2. The substance of the skin must be left in as good condition as possible, which is best effected

a) by using fresh soaking liquors,

b) by leaving the leather not longer than necessary in the baths of the lime-house,

c) by avoiding too prolonged or intense bating.

3. Skins containing fat must be degreased.

4. The tannage should yield a full leather, free from spots or stains, and leave the grain smooth and soft.

5. After tanning, the leather must be freed from acid as thoroughly as possible (see remarks further on).

6. The flesh-side must be shaved.

7. The fat liquor must penetrate the leather perfectly, without however imparting a fatty or sticky feel either to the grain or the flesh side.

8. The leather must not be dried before it is dyed or blackened, and should be protected as much as possible from light.

When all the afore-mentioned conditions have been fulfilled, the leather is ready for dyeing either

I. with Acid Colours direct, or

II. with Basic Colours, after bottoming with vegetable tannage materials; or again,

III. by a combination of both methods, or is ready

IV. for blackening. 


\section{Neutralising Chrome Leather.}

All chrome leather, inmaterial whether tanned by the two-bath or one-bath process, contains free acid which cannot be removed by simply washing with water. The following methods may be applied to effect neutralisation:

1. The leather, according to the amount of acid it contains, is treated in the drum for $1 / 2-3 / 4$ hour with a solution of at least $2 \%$ borax, and then washed thoroughly in water. Or

2. the leather is milled in the drum for $1 / 2$ hour with a solution of at least $2 \mathrm{lbs}$ phosphate of soda per $100 \mathrm{lbs}$ of leather, and, this liquor having been run off, milled again for $1 / 4$ hour with a solution of $0,05-0,1 \%$ sodium bicarbonate.

The temperature of the bath for neutralising should not exceed about $30^{\circ}$ C. ( 85 deg. F.).

The leather treated as per method 1 is almost completely free from acid; when treated according to method 2 it is neutralised entirely.

\section{Directions for Dyeing and Applying the Dyestuffs.}

Chrome leather is as a rule dyed either with Acid or Basic Colours, to best advantage in the drum, because it is essential that the leather be worked very thoroughly.

\section{Acid Colours on Chrome Leather.}

For dyeing 100 lbs moist leather (weight after shaving) which has been fat-liquored, add the dyestuff solution heated to $50-60^{\circ} \mathrm{C}$. $(120-140 \mathrm{deg}$. F.) to the drum, and drum for 15 to 25 minutes. If specially good penetration is desired, $3 / 4-11 / 2$ oz ammonia is added to the contents of the drum. After the stated time the dyebath is acidulated with sulphuric or formic acid, using 1 part by weight of formic acid of $50 \%$, or half the quantity of sulphuric acid (conc.) for every 2 parts dyestuff in addition to the quantity of acid necessary for neutralising the ammonia which may have been added. 
After the addition of the acid the leather is worked for another 10 minutes, at the end of which all the dyestuff must be fixed.

Should the leather require a filling, it may be subjected to re-tannage with vegetable tanning materials (sumac or gambier) in discretionary quantities. The solution of the tamning materials may be added straight to the exhausted dyebath. Such a re-tannage yields a leather allowing of an easier and better dressing.

The following Acid Colours are principally used for the customary shades on chrome leather:

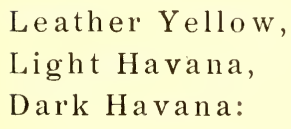

Ox-blood,

Cherry Red,

Russian Red, etc.:

Tobacco Brown,

Chocolate and other

dark Mode Shades:

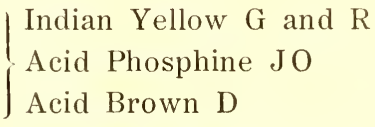

Indian Yellow $\mathrm{G}$ and $\mathrm{R}$

Acid Phosphine JO

Acid Brown D

Havana Brown S conc.

For shading purposes:

Naphtol Black B

Naphtol Blue Black.

Havana Brown S conc.

shaded with

Acid Brown D

Indian Yellow $\mathrm{G}$ and $\mathrm{R}$

Naphtol Black B

Fast Acid Green BN, etc.

New Red B for leather

Naphtol Red EB

Roccelline,

shaded with the above-named brown dyestuffs.

If the chrome leather, after dyeing with Acid Colours, is to be fatliquored, it is recommended to top such dyeings with Basic Colours. which renders them faster to alkalies.

The topping may be carried out directly after the dyeing and in the exhausted dyebath; for this operation $1^{1 / 2}-8$ oz of the following dyestuffs are required per $100 \mathrm{lbs}$ of leather:

$\begin{array}{ccc}\text { Diamond } & \text { Phosphine G G } \\ , " & , & \text { P G } \\ ", & , & \text { R } \\ ", & , & \text { D, }\end{array}$

either alone or in mixture with

Bismarck Brown EE or

Leather brown A. 
Grey and beige shades are likewise produced with Acid Colours, proceeding however as follows: The neutralised leather is drummed with the fatliquor to which $1 / 2$ to $4 \mathrm{oz}$ of dyestuff have been added per $100 \mathrm{lbs}$ leather, according to the depth of shade to be dyed. The leather having been drummed for half-an-hour, a decoction of 6-8 lbs sumac, or a solution of 3-4 lbs gambier, is added to the dyebath, and the leather worked for another $1 / 2$ hour, being then rinsed and set out.

The following dyestuffs are used for Grey:

Neutral Black B or B N for leather Nerazine G,

shaded with any of the above-mentioned Acid Colours.

Beige, Champagne colour,

$$
\text { etc.: }
$$

\author{
Indian Yellow $\mathrm{R}$ \\ Acid Phosphine JO \\ shaded with \\ Havana Brown S conc. \\ Acid Brown D
}

Neutral Black B for leather.

\title{
II. Basic Colours on Chrome Leather.
}

The neutralised leather is first treated in the drum with a solution of vegetable tanning materials. Sumac, and frequently also gambier, either alone or in combination with each other or with fustic extract etc., are mostly used for this purpose; for treating $100 \mathrm{lbs}$ leather, the following quantities of a solution of tanning materials of $17^{\circ}$ Barkometer are required:

for light shades $1^{1 / 2}$ gallons, for dark shades up to $2^{1 / 2}$ gallons.

Larger quantities of tanning materials alter the character of the chrome leather more or less, without giving better results in the dyeing.

Leather treated in this manner is dyed with Basic Colours exactly in the same way as bark-tanned leather.

The dyeing in the drum or in the paddle is the method mostly used, though in some cases tray-dyeing, and even staining, may be resorted to on occasions.

The duration of the dyeing process is about 10 to 20 minutes at a temperature of $45-50^{0} \mathrm{C}$. $(115-120 \mathrm{deg}$. F.). During this time, the dyestuff almost completely exhausts. With very deep shades it is an advantage to add the dyestuff in two portions and to dye a few minutes longer if necessary. 
The following dyestuffs serve for the production of the most current shades and may be combined in any proportion:

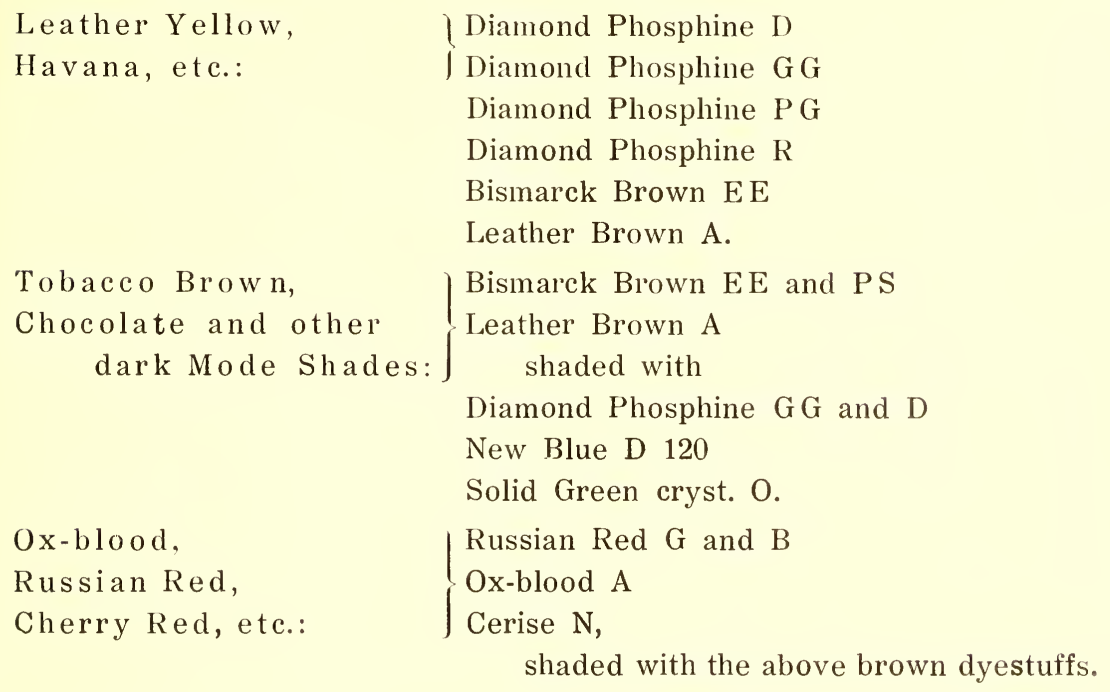

Tobacco Brown, Chocolate and other dark Mode Shades:

Bismarck Brown EE and PS

Leather Brown A shaded with

Diamond Phosphine GG and D

New Blue D 120

Solid Green cryst. O.

Ox-blood,

Russian Red, Cherry Red, etc.:

Russian Red G and B

Ox-blood A

Cerise $\mathrm{N}$,

shaded with the above brown dyestuffs.

\section{Dyeing by the Combination Method.}

This method is applied always in such cases where the results obtainable by the methods described sub I and II are not satisfactory, i. e. generally for leather the grain of which is not so well suited for the production of coloured leather. This applies chiefly to chrome=tanned sheep skins.

The neutralised leather is first fatliquored. For chrome-tanned sheep skins, which contain naturally a considerable amount of fat, a fatliquor is used that contains chiefly soap and egg-yolk and only very little neatsfoot oil.

After the fatliquoring the leather is bottomed in the drum with a suitable combination of wood colours. After $1 / 2$ hour's drumming slight quantities of sulphate of iron or sulphate of copper are added to fix the wood colours. After further 10 minutes, a solution of Anthracene Colour's is added to the same bath, for which purpose

Anthracene Yellow C Powder and

Anthracene Acid Brown B

come chiefly into consideration. After drumming for about 25 minutes with these dyestuffs, the bath is acidulated with $11 / 2-3 \mathrm{oz}$ of acetic acid (per $100 \mathrm{bbs}$ of leather), the leather being finally topped with Basic Colours, for which purpose

Diamond Phosphine GG and D,

Bismarck Brown EE, FFG and GG, and

Leather Brown A

are principally used. 


\section{Black on Chrome Leather.}

Chrome leather may be dyed black in a great variety of ways. It is generally dyed in the drum, by which method a full shade of black may be obtained straightaway, or, it is bottomed in the drum, the grain then being blackened with suitable black dyestuffs according to any method desired. When bottoming, blue or violet dyestuffs are often added to obtain a brighter shade on the flesh side.

Two groups of dyestuffs come mainly into consideration for drum dyeing, viz., black Acid Colours and black Substantive Colours, the selection of which is dependent on the condition of the leather, that is to say, whether it still contains a little acid or none at all.

\section{Black Acid Colours:}

Neutral Black B for Leather

Neutral Black BN for Leather

Acid Black B for Leather

Acid Black $\mathrm{C}$ for Leather

Nerazine G.

These products may be used on any kind of chrome leather in all such cases where direct black shades are to be produced in the drum, even where the chrome leather for some reason or other has been neutralised only in part or not at all.

\section{Black Substantive Colours: \\ Chrome Leather Black C \\ Chrome Leather Black $8189 \mathrm{~J}$ \\ Chrome Leather Black $8749 \mathrm{~J}$ conc. \\ Chrome Leather Black $2061 \mathrm{~J}$ \\ Leather Black JE extra conc.}

Any of these dyestuffs are suited for dyeing chrome leather which has been fully neutralised or almost entirely so.

The afore-stated dyestuffs may be used in combination with one another or together with Acid Colours, and may also be mixed at will with logwood extract.

All the dyestuffs mentioned are applied alike according to one or other of the following two methods:

\section{A. Direct Black in the Drum.}

The leather is drummed for $1 / 2$ hour with the dyestuff solution; should the bath not be fully exhausted, it is slightly acidulated with acetic acid $(1 / 2-1 \mathrm{oz}$ per $100 \mathrm{lbs}$ leather) and the drumming continued 
for another 10 minutes. Should a treatment with logwood extract prove necessary for filling purposes, a solution of the same may be added straight to the dyebath. The fatliquoring may be done either before or after the dyeing.

About $1-2 \mathrm{lbs}$ of the afore-mentioned dyestuffs are required for every $100 \mathrm{lbs}$ of leather.

\section{B. Bottoming in the Drum and Topping with Basic Colours.}

The leather is first dyed for $1 / 2$ hour in the drum, in order to dye the flesh-side grey, purple or blue. For this purpose, the above-named dyestuffs are used in combination with violet or blue Acid Colours, chiefly the following:

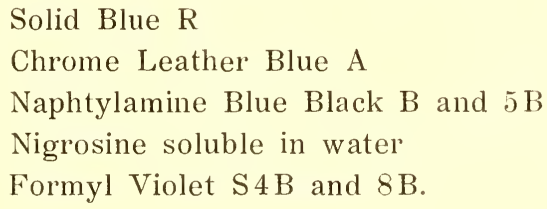

Of the black dyestuffs mentioned, about 3 to $12 \mathrm{oz}$ are sufficient and of the blue and violet dyestuffs $3 / 4$ to $3 \mathrm{oz}$, for $100 \mathrm{lbs}$ leather.

Logwood extract may for this method be added to the dyebath in any quantity desired.

The fatliquoring of the leather is best effected by adding the fatliquor to the exhausted dyebath and then drumming for another $1 / 2$ hour.

The leather bottomed in this fashion is then topped with Basic Colours, which operation may be carried out either in the drum or the tray, or by staining.

The following dyestuffs come into consideration for this purpose:

\section{Leather' Black 'TB B \\ Leather Black TB \\ Leather Black T G.}

Topping in the drum is done in a fresh bath, $6 \mathrm{oz}$ to $1 \mathrm{lb}$ of dyestuff being sufficient for $100 \mathrm{lbs}$ of leather. A slight addition of acetic acid to the bath is to be recommended. After working for 10 to 15 minutes, the dyestuff becomes fixed.

When the topping is done in the tray, the skins are folded together lengthways, the grain outside, and dipped in the tray in the same way as bark-tanned leather, 1 to $3 \mathrm{oz}$ of Leather Black being sufficient for 1 doz skins. 
When the grain is to be blackened by staining, a solution is prepared of 10 to $12 \mathrm{oz}$ Leather Black per 10 gallons water, slightly acidulated with acetic acid (see page 1) and then applied to the leather.

Any dyestuff solution used for the dyeing of blacks on chrome leather should have a temperature of about $45-55^{\circ} \mathrm{C}$. $(115-130 \mathrm{deg}$. F.). 
III.

CHAMOIS LEATHER. 



\section{Preparation of the Leather.}

Chamois leather must first of all be freed from any remnant of oil that has remained unfixed, or from any acid or soda that may still be present. In order to ensure the removal of all these substances, the leather is soaked in lukewarm water and then washed well in water containing $1 / 2-1$ per cent of borax. If the wash liquor has a milky appearance, the leather is rinsed again in lukewarm water.

\section{Dyestuffs to be employed.}

Chamois leather may be dyed with the Acid and Basic Colours mentioned before, according to the respective recipes, provided there are no requirements made with regard to fastness to washing. In view, however, of absolute fastness to washing being essential in by far the majority of cases, the Immedial Colours are usually found the most suitable, of which the following come in the first place into consideration:

$\begin{array}{ll}\text { For yellow: } & \text { Immedial Yellow D; } \\ \text { for yellowish brown: } & \begin{array}{l}\text { Immedial Yellow Brown EN } \\ \text { Immedial Cutch G; }\end{array} \\ \text { for reddish brown: } & \text { Immedial Cutch O } \\ \text { for claret: } & \text { Immedial Bordeaux G conc. } \\ \text { for greyish brown: } & \text { Immedial Maroon B conc. } \\ & \text { Immedial Dark Brown A } \\ \text { for olive: } & \text { Immedial Olive } 3 \mathrm{G} \\ \text { for green: } & \text { Immedial Green G G extra; } \\ \text { for blue: } & \text { Immedial Sky Blue Powder conc. } \\ & \text { Immedial New Blue G conc; } \\ \text { for black: } & \text { Immedial Black NN conc. }\end{array}$

$$
\text { , } \quad, \quad \mathrm{NB} \text {. }
$$




\section{The dyestuffs are applied as follows:}

Dissolve the Immedial Colours in boiling water with the addition of their own weight of sodium sulphide crystals; then allow to cool, and add of formalin one-tenth, and of soap (dissolved in a little water) onefifth, of the weight of dyestuff.

Dye the leather by kneading or drumming for $1 / 2$ hour in the cold solution; then rinse, and wash in a soap solution of about $1 \%$. If the leather be required to be specially smooth, $1 / 3-1 / 2 \mathrm{oz}$ egg-yolk is advantageously added to the soap solution for every skin.

If particularly high demands are made of the dyeings with regard to fastness to rubbing and washing, they should be subjected before soaping to an aftertreatment with a solution of

$$
\begin{aligned}
& 11 / 2 \text { oz sulphate of copper, } \\
& \begin{array}{ll}
11 / 2 \mathrm{OZ} \text { bichromate of potash and } \\
8 \mathrm{OZ} \text { acetic acid of } 50 \%
\end{array}
\end{aligned}
$$

The dyed leather is drummed or kneaded in this solution for $1 / 4$ hour, and then rinsed thoroughly.

Black on chamois leather has frequently to be produced by staining, which is carried out in the following manner:

Prepare as above stated a solution of

5 lbs Immedial Black $\mathrm{N} \mathrm{N}$ conc.

5 lbs sodium sulphide crystals

$1 \mathrm{lb}$ formaldehyde

$1 \mathrm{lb}$ soap

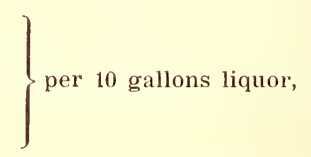

and apply this solution to the dry leather by means of a brush. After this coating has been absorbed by the leather, another solution is applied in exactly the same manner, consisting of

$$
\left.\begin{array}{l}
8 \text { oz sulphate of copper } \\
8 \text { oz bichromate of potash } \\
2^{1 / 2} \text { lbs acetic acid of } 50 \%
\end{array}\right\} \text { per } 10 \text { gallons water. }
$$

The leather is then rinsed several times with water, squeezed, and dried.

For shading black dyeings produced in this manner, Immedial Bordeaux G conc. is used. 
$1 *$

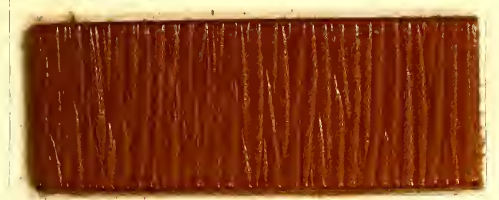

1 oz Diamond Phosphine PG

$1 / 32$ "New Blue D 120

$3 *$

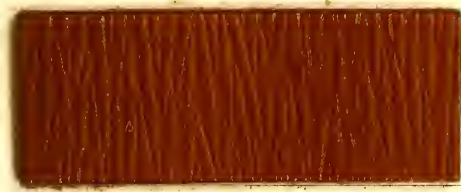

8 oz Diamond Phosphine D.

$5 *$

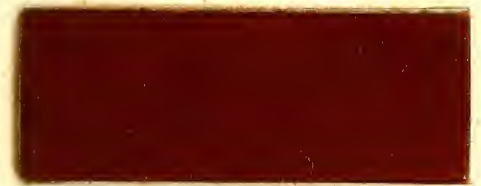

5 oz Diamond Phosphine R

11 "Diamond Phosphine D.

$7 *$

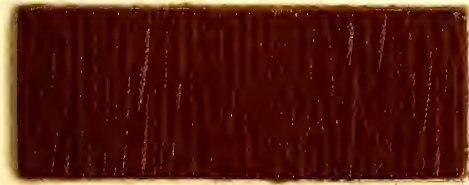

13 oz Diamond Phosphine D

3 " Bismarck Brown GG

1/3 "New l3lue D 120.

$9 *$

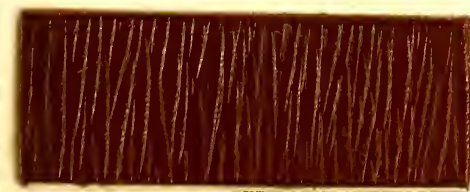

9 $/ \%$ 0\% Diamond Phosphine D)

$6^{1 / 3}$, Diamond Phosphine $\mathrm{i}$ G

$1 \%$ : , Leather Brown A.

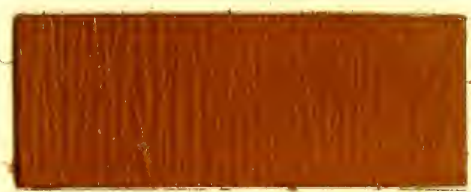

1³ oz Diamond Phosphine GG

12/3 "Diamond Phosphine D.

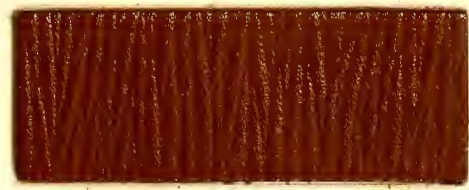

1 Ib Diamond Phosphine D.

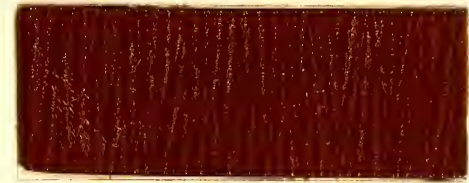

5 oz Bismarck Brown G G

11 " Diamond Phosphine D.

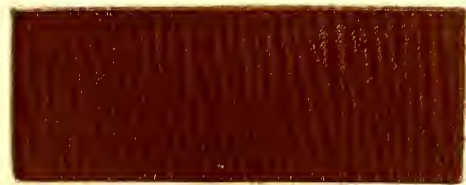

12 oz Diamond Phosphine $\mathrm{D}$

"Bismarck Brown G G

$3 / 4 \quad$ New Blue D 120 .

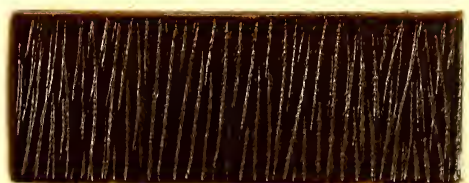

8 oz Diamond Phosphine G G

8 "Bismarek Brown l's

$3 / 4$, Methylene I3lue I) I3 13. 



\section{Bark-tanned Hide.}

$11^{*}$

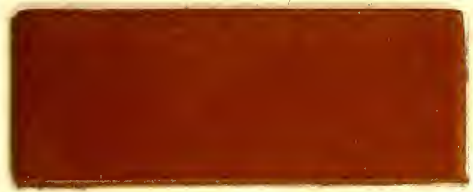

1 lb Diamond Phosphine G G.

$13^{*}$

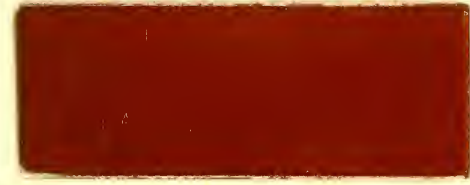

$1 \mathrm{lb}$ Diamond Phosphine R.

$15+$

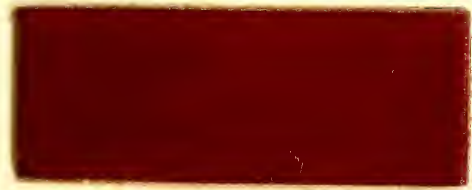

1 lb Brilliant Croceïne MOO Formic acid.

$17 *$

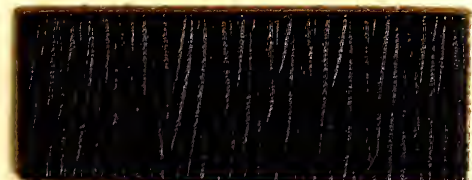

$80 \%$ New Blue FL.

$19 *$

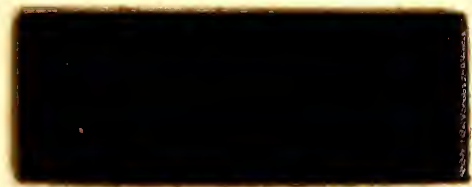

1 ib Leather Black TB pat.

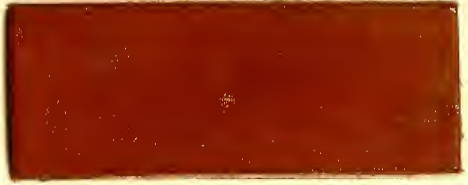

1 lb Diamond Phosphine $\mathrm{PG}$.

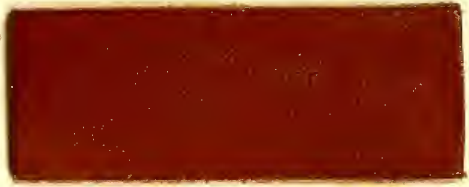

1 lb Havana Brown S cone. Formic acid.

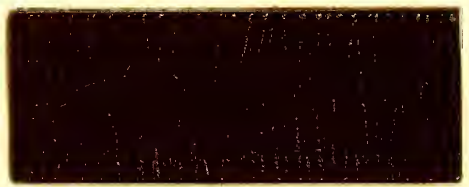

12 oz Russian Red G

3 „Bismarck Brown GG.

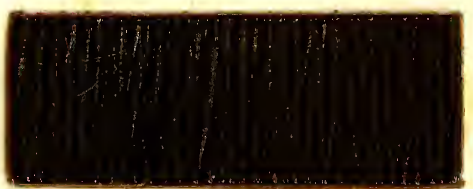

3 oz New Blue F L

12 "Diamond Phosphine GG.

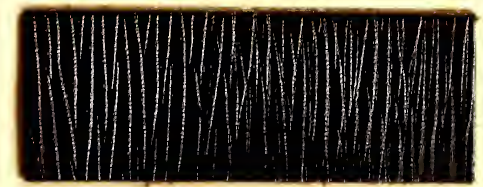



East Indian Goat Skins.

$21 \dagger$

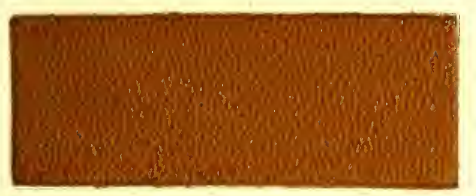

16 oz Indian Yellow G

"Acid Brown D

" Naphtol Black B

sulphuric acid.

$23+$

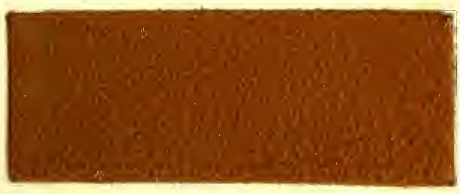

$8^{1 / 2} \mathrm{oz}$ Indian Yellow $\mathrm{G}$

$12 \frac{1}{2}$ "Havana Brown S conc.

$1^{1 / 4}$, Naphtol Black B

sulphuric acid.

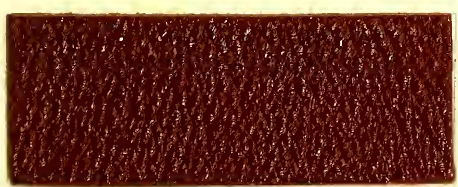

$25 *$

19 oz Diamond Phosphine D

2 "Bismarck Brown GG.

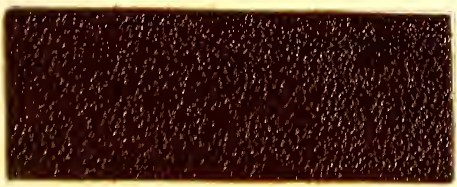

121/2 0\% Diamond l'hosphine D

$61 / 1$, Bismarck Brown (i G

2 "New I3lue D 120.

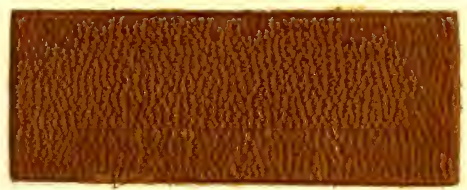

16 oz Indian Yellow G

"Acid Brown D

2 "Naphtol Black B sulphuric acid.

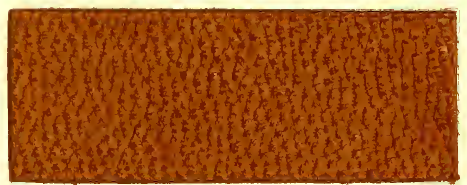

16 oz Indian Yellow $\mathrm{G}$

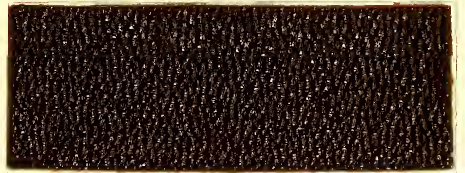

$14^{3} / 1 \mathrm{oz}$ Bismarck Brown G G

61/4 " Diamond Phosphine G G

1 " Methylene Blue DBB.

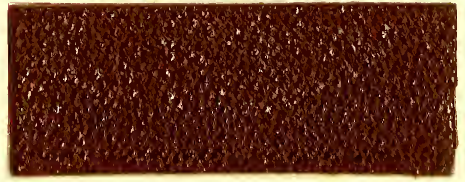

$210 \%$ Diamond Phosphine I) 



\section{East Indian Goat Skins.}

$29 \S$

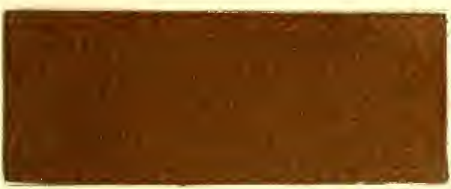

6 oz Neutral Black B for Leather

1 " Orange EN Z

soap.

$31 \S$

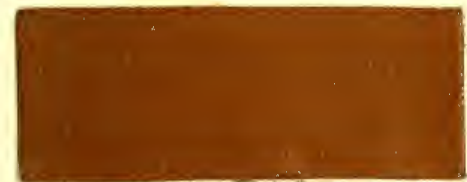

$1 \frac{1 / 2}{2} \mathrm{ZZ}$ Neutral Black B for Leather

1 \# Orange extra

soap.

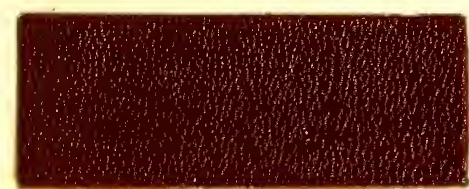

21 oz Bismarck Brown PS.

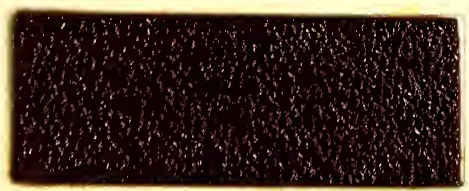

16 $0 \%$ Cerise N.

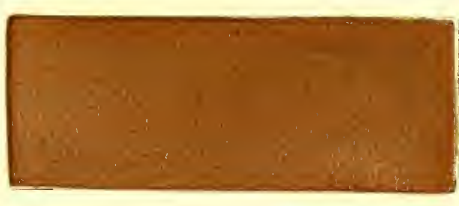

$3 \mathrm{oz}$ Neutral Black B for Leather

1 ” Orange extra

soap.

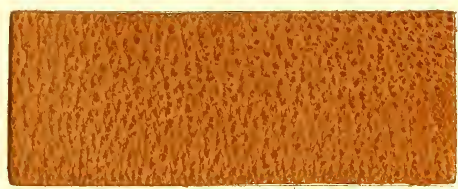

2 oz Diamond Phosphine PG $1^{1 / 2} \mathrm{dr}$ New Blue D 120.

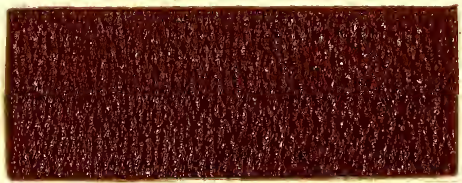

$21 \mathrm{oz}$ Tamnin Brown B for Leather.

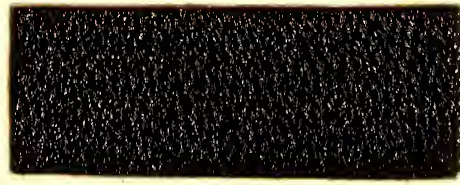

$210 \%$ Leather IBlack T B pat. 


\section{Bark-tanned Calf Skins.}

$37 *$

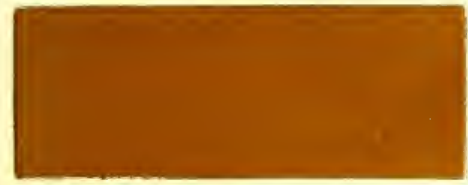

2 oz Diamond Phosphine GG

3 " Diamond Phosphine D.

39 *

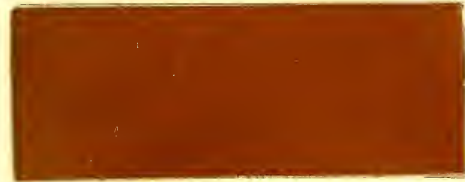

16 oz Diamond Phosphine PG 5 dr New Blue D 120 .

$41^{*}$

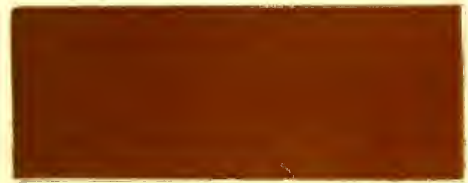

16 oz Diamond Phosphine D

5 dr New Blue D 120.

$43^{*}$

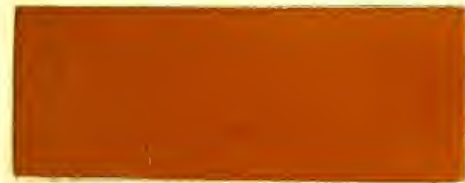

61/1 0\% Diamond Phosphine D

4 " Diamond Phosphine R.

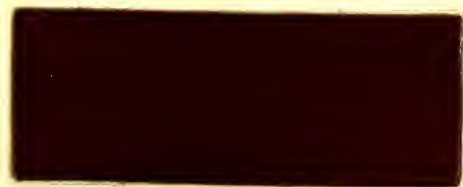

$16 \%$ Russian Red G.

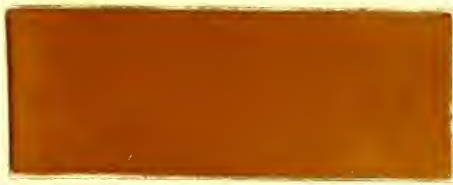

71/: oz Diamond Phosphine GG

$7^{1 / 3}$, Diamond Phosphine D.

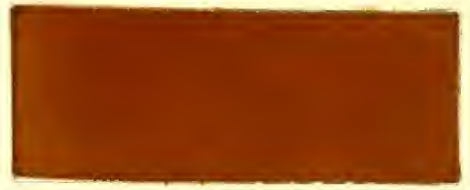

16 oz Diamond Phosphine D.

1 "Diamond Phosphine PG.

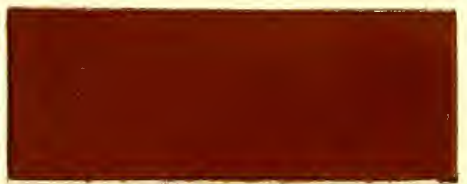

16 oz Diamond Phosphine D

5 "Bismarck Brown G G

$5 \mathrm{dr}$ New Blue D 120.

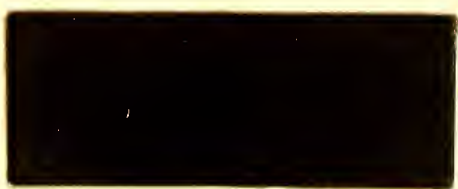

2 oz Diamond Phosphine D
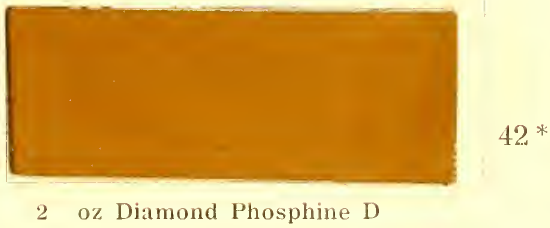

$210 \%$ Leather Black 'T' pat. 



\section{Sumac-tanned Calf Skins.}

$47 \S$

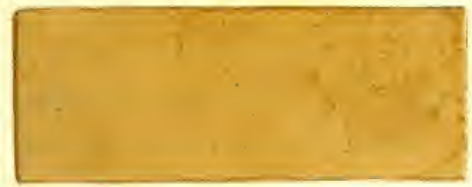

2 oz Havana Brown S cone. soap.

$49 \S$

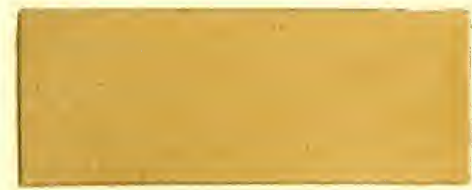

2 oz Havana Brown S conc.

$1 / 2$ "Neutral Black B for Leather soap.

$51 *$

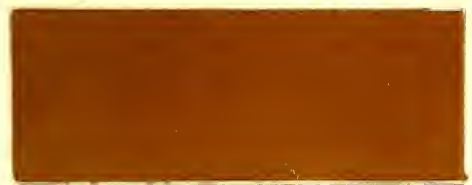

16 oz Diamond Phosphine GG

1/. " Neutral Violet extra.

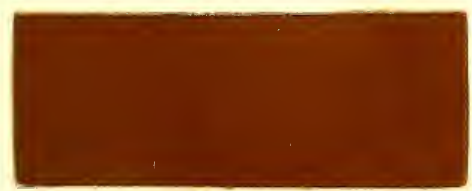

21 oz Havana Brown S conc. sulphuric acid.

$55 \dagger$

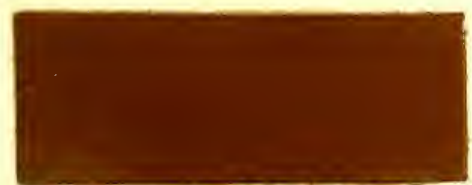

$210 \%$ Havana Brown S conc.

$\because / 1$, Naphtol Black B sulphuric acid.

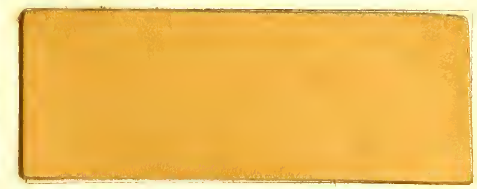

5 oz Havana Brown S conc. soap.

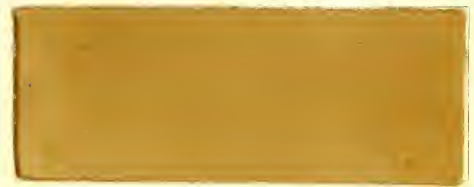

5 oz Havana Brown S conc.

2 "Neutral Black B for Leather soap.

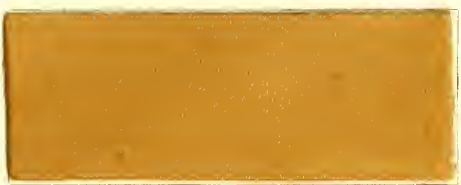

$50 \S$

2 oz Havana Brown S cone. sulphuric acid.

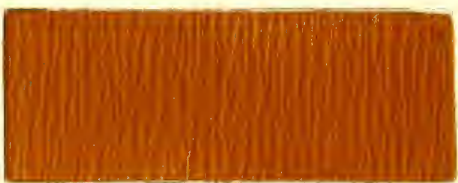

81/2 0z Diamond Phosphine GG $12^{1 / 2}$, Diamond Phosphine D.

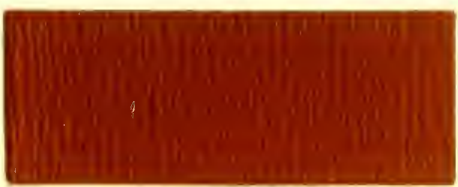

14/10\% Diamond Phosphine () $61 / 4$ " Bismarek Brown (i G. 


\section{Sumac-tanned Calf Skins.}

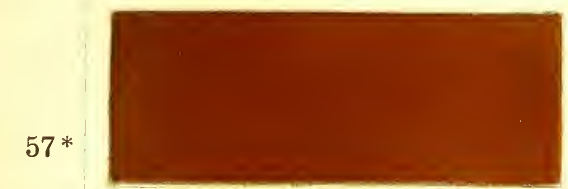

21 oz Diamond Phosphine D.

$59 *$

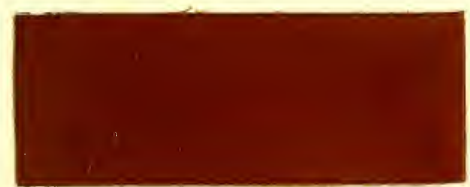

$14^{3} / 40 z$ Diamond Phosphine D

4 "Bismarck Brown G G

2 " Leather Brown A.

$61 *$

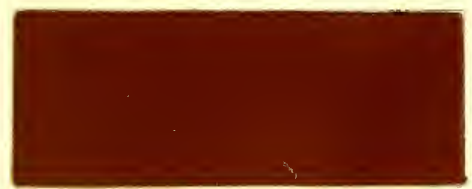

$16 \mathrm{oz}$ Diamond Phosphine D

5 , Bismarck Brown G G

6 dr New Blue D 120.

$63 *$

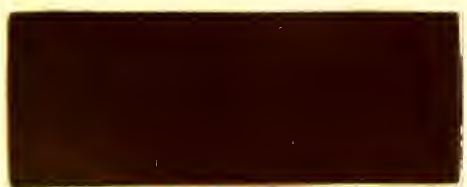

121/z Oz Leather Brown A

4 "Diamond Phosphine GG

6 dr Methylene Blue DBB.

$65 *$

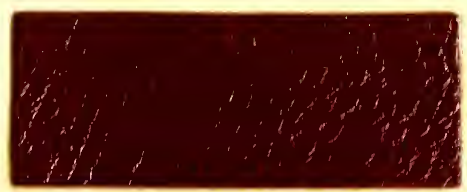

$210 \%$ Safranine S No 150.

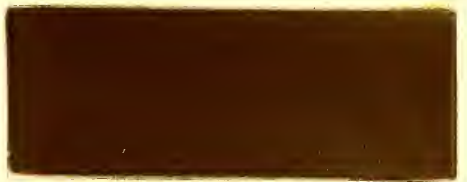

21 oz Havana Brown S conc.

$3 / 4$ "Naphtol Blue R sulphuric acid.

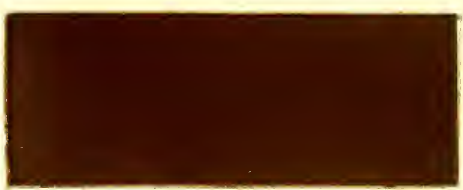

6 $1 / 1$ oz Diamond Phosphine G G

14 $3 / 4$, Bismarck Brown G G

$3 / 4$, Methylene Blue D BB.

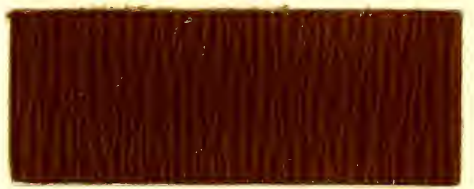

121/2 oz Diamond Phosphine D

$8^{1 / 2}$, Bismarck Brown GG

$: 3 / 4$, New Blue D 120.

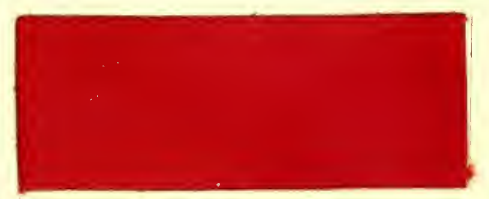

26 oz Brilliant Croceïne MOO

\section{sulphuric acid.}

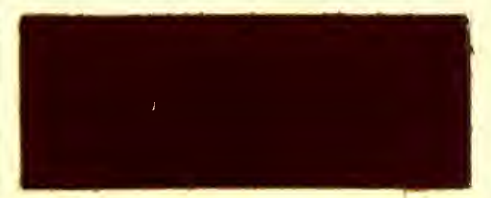





\section{Sumac-tanned Calf Skins.}

$67 \S$

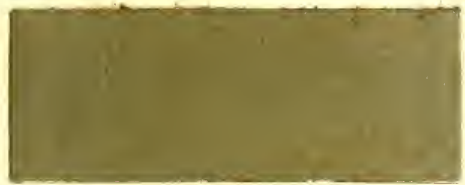

2 oz Nerazine G

soap.

$69 \S$

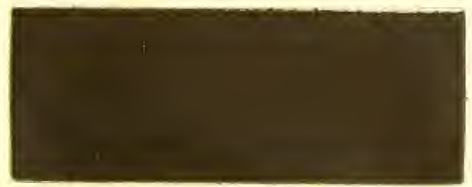

$21 \mathrm{oz}$ Neutral Black B for Leather soap.

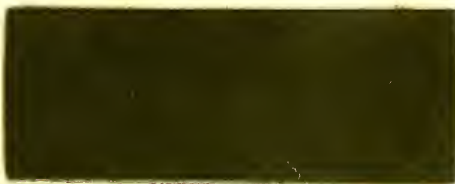

$21 \mathrm{oz}$ Naphtol Green B sulphurie acid.

$73 *$

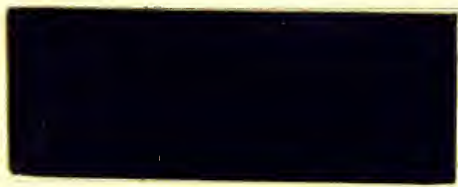

$16 \mathrm{o} \%$ Methylene Blue DBB.

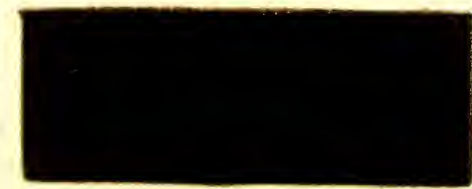

19) $0 \%$ Leather Black T B pat.

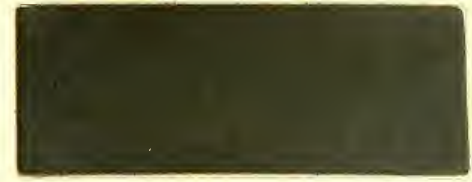

$10^{1 / 2} \mathrm{oz}$ Nerazine G soap.

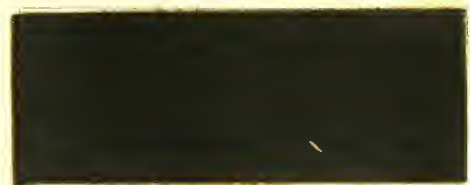

$70 \S$

2 oz Nerazine G

1/6 dr Naphtol Red C soap.

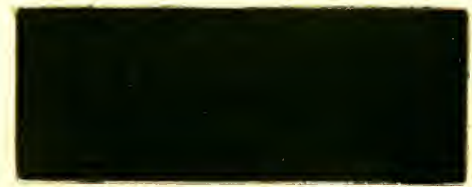

$6^{1 / 4}$ oz Methylene Blue DBB

14:/4 " Diamond Phosphine GG.

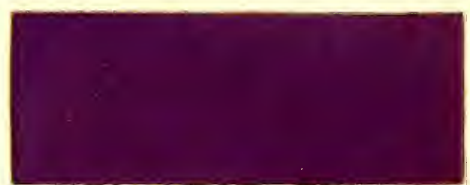

$+\quad \mathrm{oz}$ Tannin Heliotrope

$2^{1 / 2}$ dr Methylene Blue D B B.

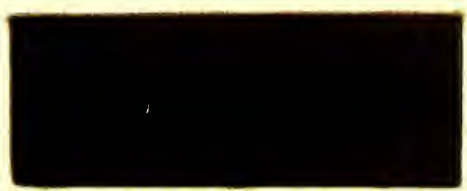

$76 *$ 


\section{Sumac-tanned Sheep Skins.}

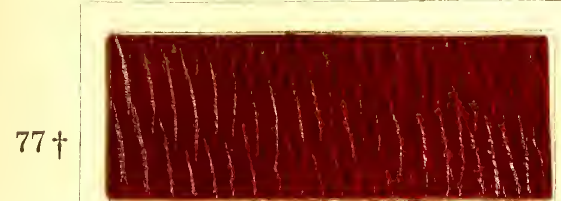

$26 \quad$ oz Brilliant Croceïne $\mathrm{BOO}$ sulphuric acid.

$79+$

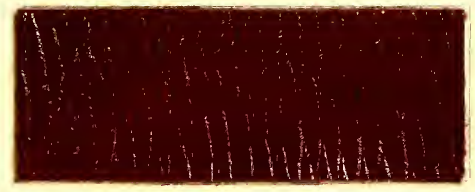

26 oz Roccelline

sulphuric acid.

$81 *$

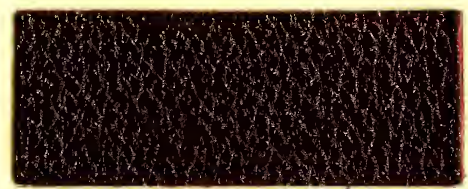

21 oz Russian Red G.

$83 *$

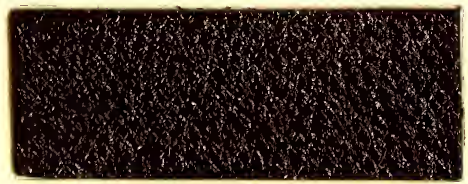

121/20\% Ox-blood A

81/4 "Diamond Phosphine R.

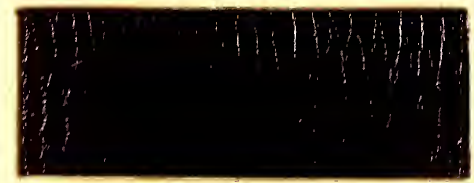

$40 \%$ Tannin Heliotrope

3 dr Methylene Blue D B B

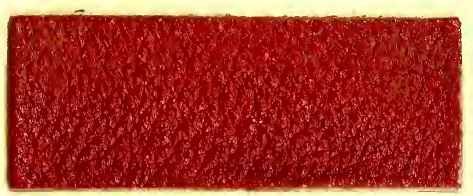

$78+$

26 oz Brilliant Croceïne M O O sulphuric acid.

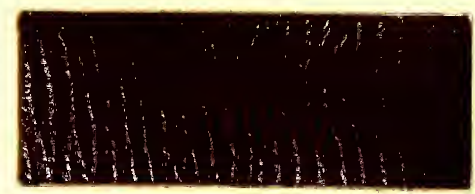

121/2 oz Russian Red A

$81 / 2$, Diamond Phosphine R.

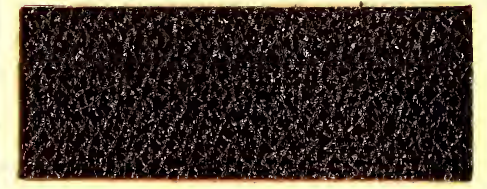

21 oz Ox-blood A.

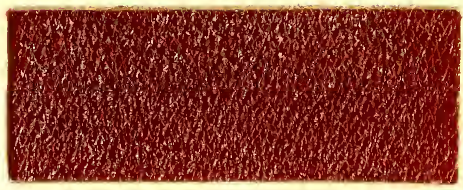

101/2 oz Bismarek Brown G G.

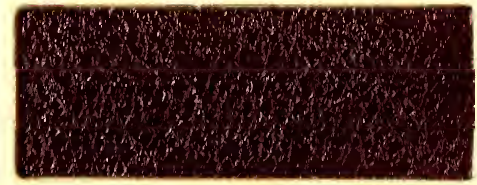





\section{Sumac-tanṇed Sheep Skins.}

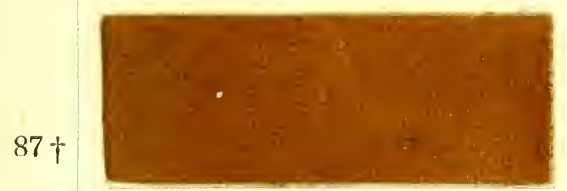

4 oz Havana Brown S cone.

$89 *$

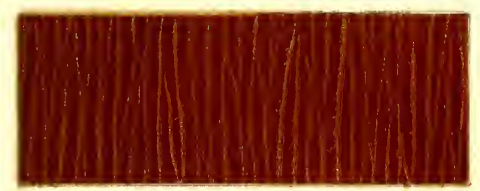

19 oz Diamond Phosphine D

2 "Bismarck Brown G G.

$91 *$

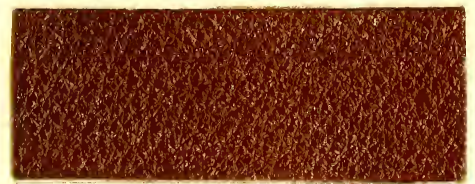

101/ะ $\mathrm{OZ}$ Diamond Phosphine D

$3 \mathrm{dr}$ New Blue D 120.

$93+$

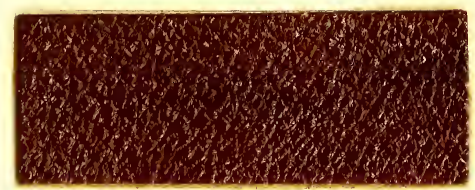

21 oz Havana Brown S eone. sulphuric acid.

$95 *$

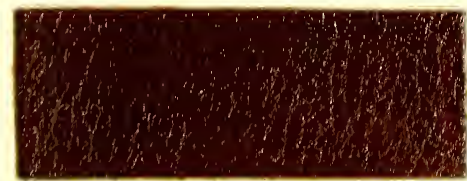

$170 \%$ Diamond Plıosphine D

3 "Bismarek Brown G G

9 dr New Blue D 120.

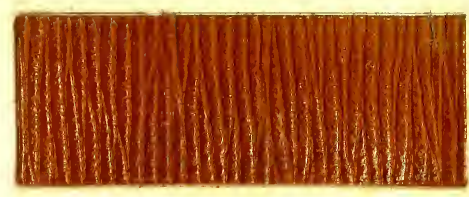

101/2 oz Diamond Phosphine D.

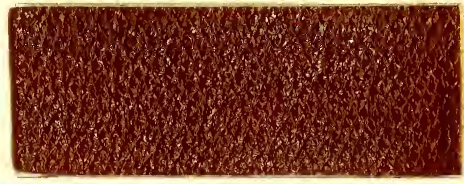

21 oz Diamond Phosphine D.

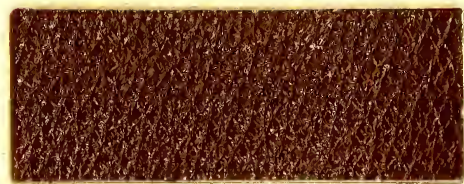

$92+$

$12^{1 / 2} \mathrm{oz}$ Havana Brown S conc.

$81 / 2$, Indian Yellow G sulphuric acid

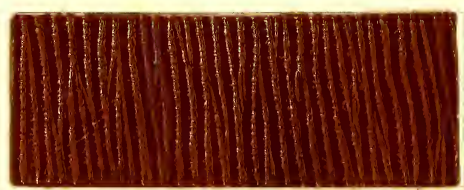

17 oz Dianıond Phosphine D

3 "Bismarck Brown G G

$6 \mathrm{dr}$ New Blue D 120.

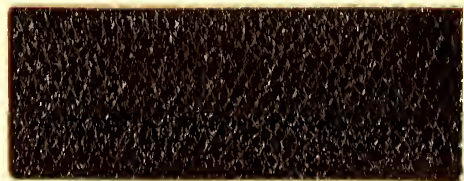

$96 *$

14:/4 0\% Diamond Phosphine I)

$61 / 4$ " Leather Brown A

9 dr New Blue 1) 120 . 
i 
Sumac-tanned Sheep Skins.

$97 \dagger$

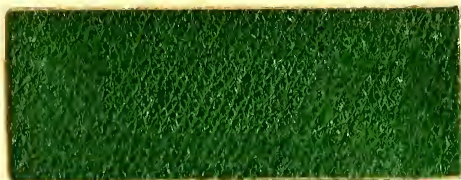

81/2 oz Acid Green 5 G

$11 / 2$ ” Indian Yellow R

sulphuric acid

$99+$

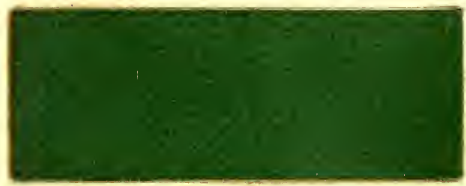

$61 /+$ oz Acid Green extra conc.

1 " Orange extra sulphuric acid

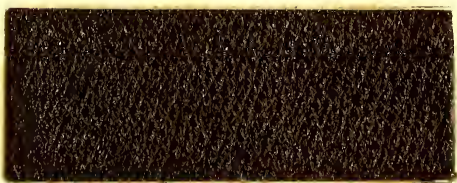

11/2 Oz New Blue D 120

16 "Diamond Phosphine GG.

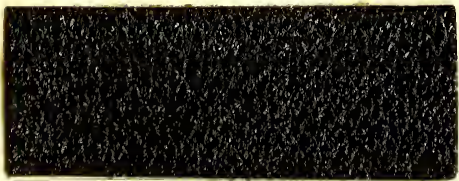

5 oz New Blue FL

16 " Diamond Phosphine GG.

$105+$

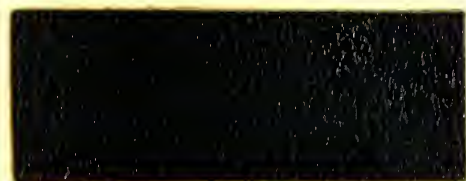

101/20\% Cyanole Green B

$1 / 2$ " Orange extra

sulphuric acid.

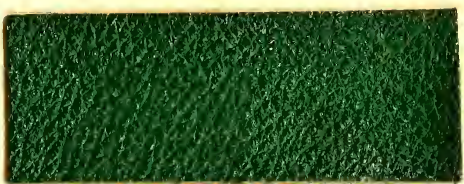

$98+$

81.20Z Acid Green $5 \mathrm{G}$ sulphuric acid.

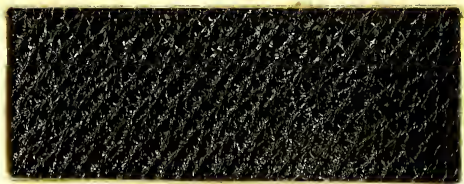

$100 *$

4 oz Malachite Green cone.

17 "Diamond Phosphine PG.

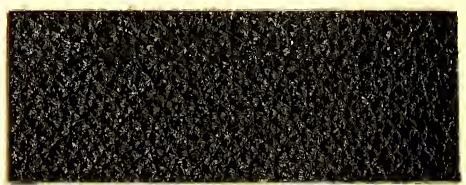

$20 z$ New Blue F L

19 „Diamond Phosphine G G.

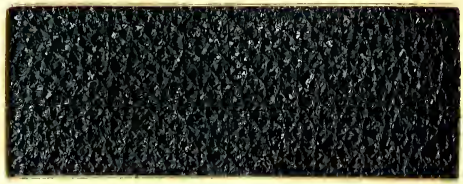

101/20z Cyanole Green B sulphuric acid.

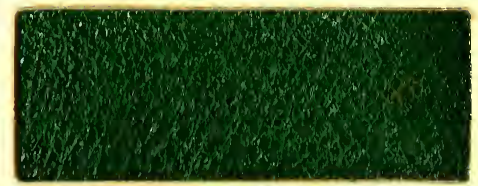

$106+$

$210 \%$ Acid Green extra conc.

5 "Indian Yellow ( sulphuric acid. 


\section{Sumac-tanned Sheep Skins.}

$107 *$

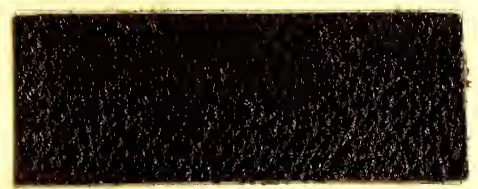

81/20z Neutral Red extra

2 " Diamond Phosphine R

3 dr Methylene Blue DBB.

$109 \S$

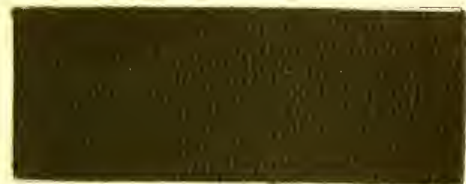

$21 \quad 0 z$ Nerazine G soap.

$111+$

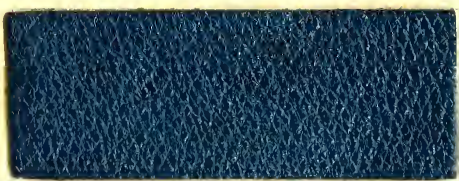

101/20 Cyanole F F sulphuric acid.

$113+$

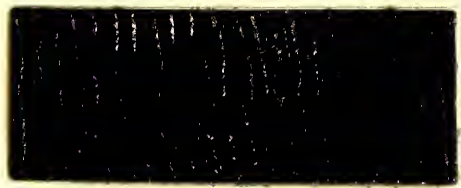

5 0\% Pure Soluble Blue sulphuric acid.

$115+$

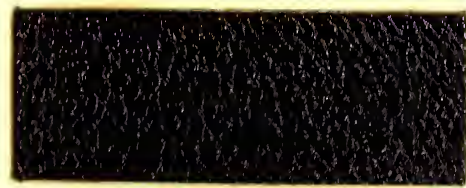

$210 \%$ Naphtol Blue R sulphuric acid.

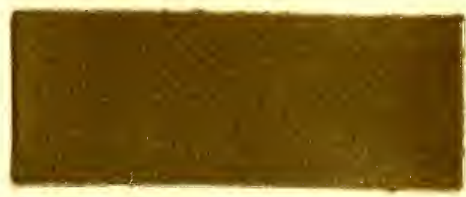

$108+$

2 oz Indian Yellow R

$10^{1 / 2}$ ” Naphtol Green B sulphuric acid,

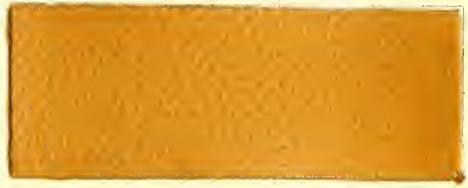

71/:3 oz Havana Brown S conc. soap.

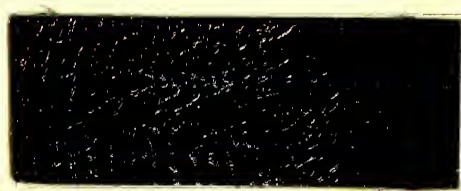

16 oz Methylene Blue DBB.

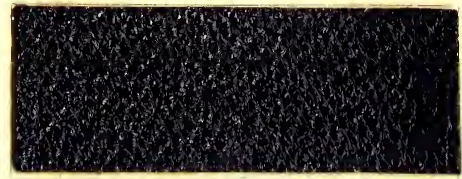

21 o\% Solid Blue R sulphuric acid.

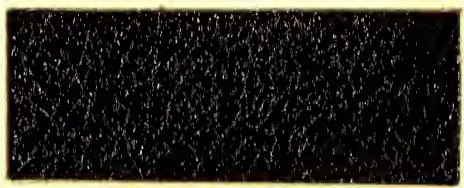

21 \% Leather Black T13 pat. 



\section{Skivers (Sheep).}

$117 \S$

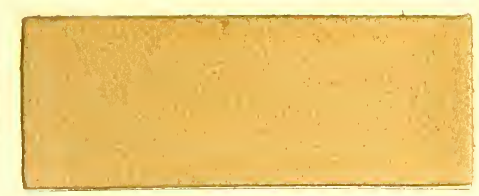

1 oz Havana Brown S eone. soap.

$119 \S$

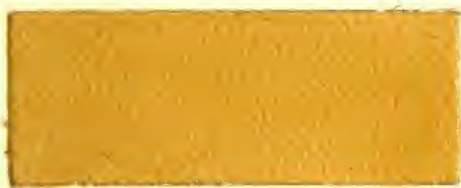

5 oz Havana Brown S conc.

1 "Neutral Black B for Leather soap.

$121+$

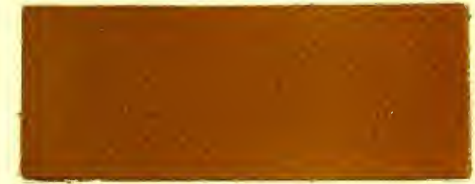

121/2 oz Indian Yellow R

81/2 "Havana Brown S cone. sulphuric acid.

$123 *$

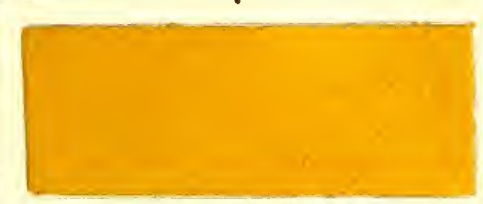

101/z 0z Diamond Phosphine GG.

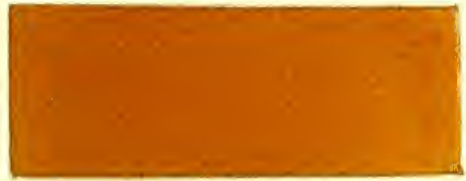

$4 \mathrm{o \%}$ Diamond Phosphine (i G

14 "Diamond Phosphine D

$3 \mathrm{dr}$ New Blue I) 120.

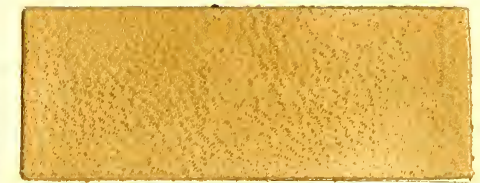

2 oz Havana Brown S conc,

$1 / 2$ "Neutral Black $B$ for Leather soap.

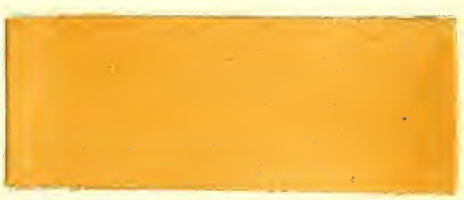

5 oz Havana Brown S conc. soap.

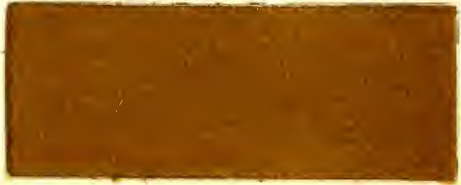

$121 / 2 \mathrm{oz}$ Havana Brown S cone.

$81 / 2$, Indian Yellow G

3 dr Naphtol Black B sulphuric acid.

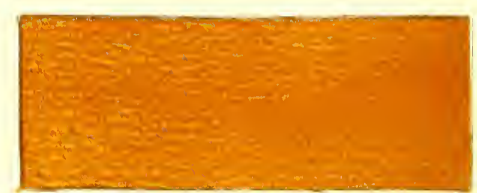

61/1 oz Diamond Phosphine G G $14 \% / 1$, Diamond Phosphine D.

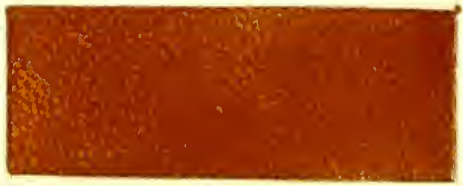

21 o\% Diamond Phosphine 1). 



\section{Skivers (Sheep).}

$127 *$

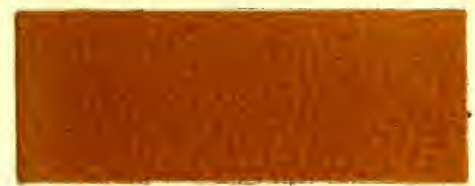

81/2 07. Bismarck Brown PS

$81 / 2$, Diamond Phosphine G G

2 " Leather Brown A.

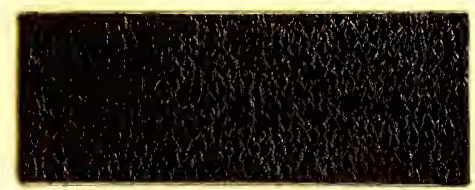

81/2 oz. Diamond Phosphine R

3 "Tannin Heliotrope

1 " Methylene Blue DBB.

$131 *$

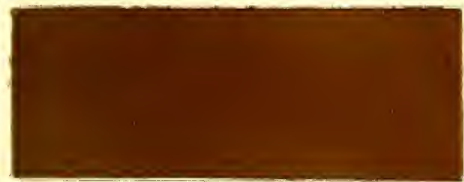

16 oz Diamond Phosphine R

1 "New Blue FL.

133 *

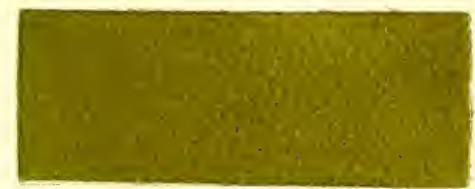

101/: 07. Diamond Phosphine R

1 " Methylene Blue DBB.

$135 *$

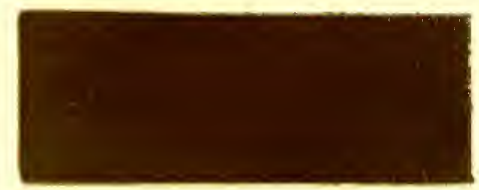

$160 \%$ Diamond Phosphine R

2 "Bismarck Brown (i G

2 "New Blue FL.

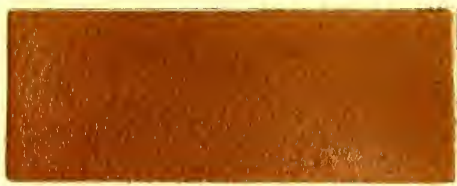

$121 / 20 z$ Nut Brown A

3 " Leather Brown $\mathrm{A}$.

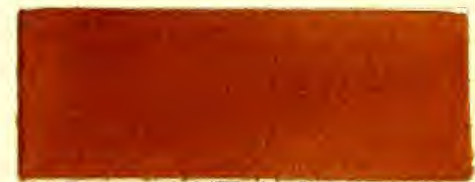

21 oz Bismarck Brown G G.

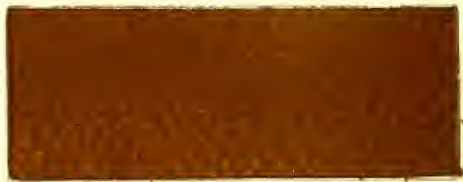

132 *

16 oz Diamond Phosphine R

"Bismarck Brown G G

"New Blue F L.

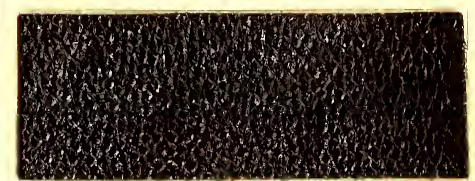

$134^{*}$

81/2 oz Diamond Phosphine GG

3 "T:mnin Heliotrope

" Methylene Blue DBB.

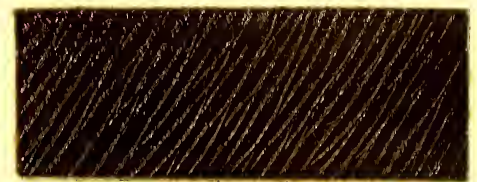

136 *

16 0\% Diamond Phosphine R

"Bismarek Brown (i

2 , New Blue FL. 



\section{Skivers (Sheep).}

137 *

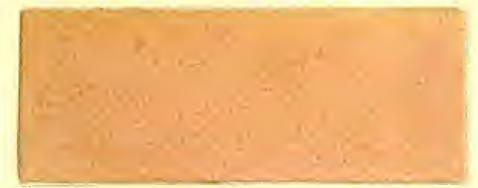

$1 \mathrm{oz}$ Rosazeine $6 \mathrm{G}$.

$139 *$

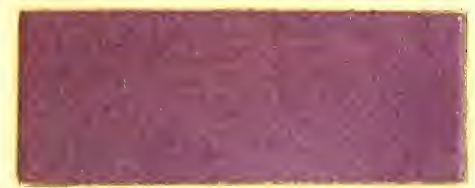

1 oz Tannin Hetiotrope

$1^{1} \mathrm{dr}$ Methylene D B B.

$141 \dagger$

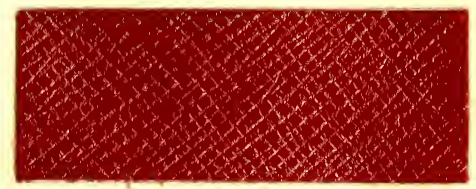

26 oz Brilliant Croceïne B O O sulphuric acid.

$143 *$

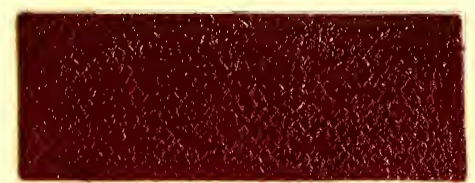

$21 \mathrm{o} \%$ Safranine G extra No 0.

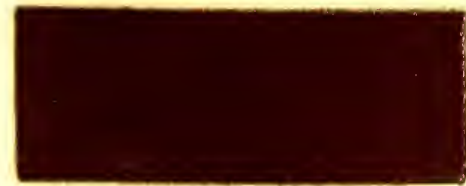

$16 \mathrm{oz}$ Ox-blood A.

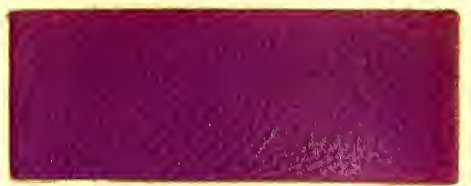

4 oz Tannin Heliotrope.

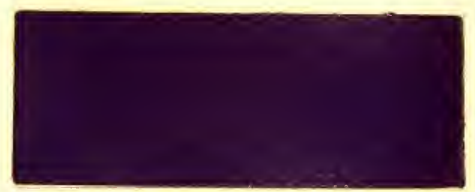

$140 *$

4 oz Tannin Heliotrope

2 " Diamond Phosphine $\mathrm{R}$

1 " Methylene Blue DBB.

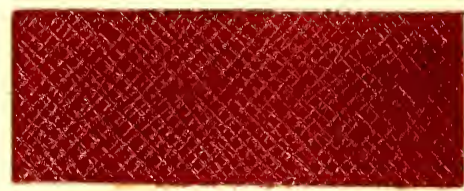

26 oz Scarlet EC sulphuric acid.

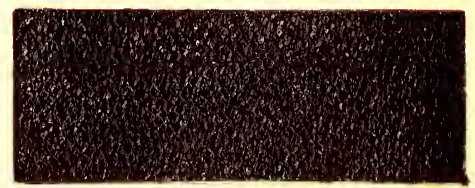

16 oz Cerise N.

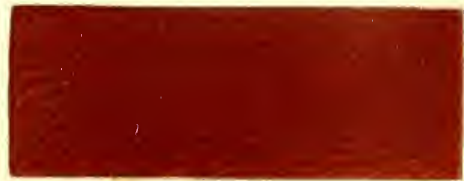

$81 / 20 \%$ Diamond Phosphine R 3 " Tamin Heliotrope. 



\section{Skivers (Sheep).}

$147 *$

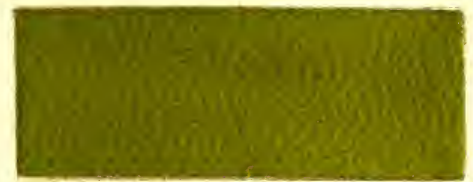

101/2 oz Diamond Phosphine G G

$1 / 2$, Methylene Blue DBB.

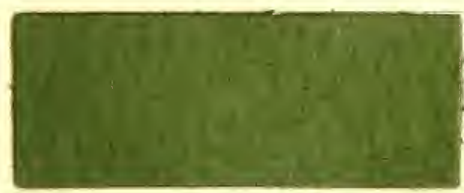

$21 \quad o z$ Naphtol Green B sulphuric acid.

$151+$

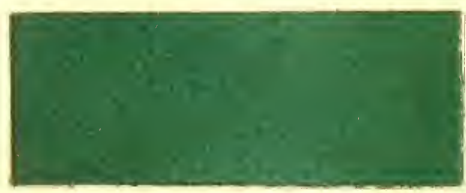

81/2 oz Cyanole FF

2 "Indian Yellow R sulphuric acid.

$153 *$

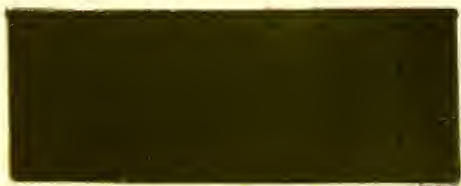

19 oz Diamond Phosphine G G 2 " New Blue F L.

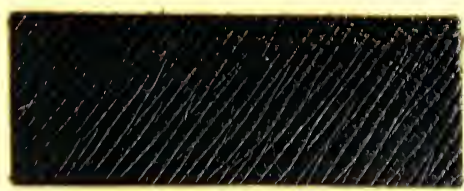

101/20\% Brilliant Naphtol B3lue I3 pat.

1 " Indian Yellow R sulphurie acid.

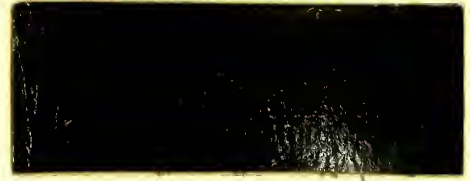

16 oz Diamond Phosphine GG

3 " Methylene Blue DBB.

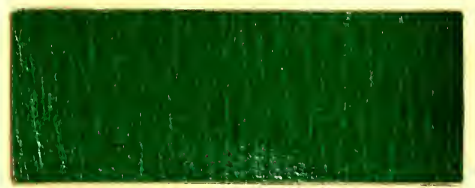

101/20 2 Acid Green $5 \mathrm{G}$

1 "Indian Yellow $\mathrm{R}$ sulphuric acid.

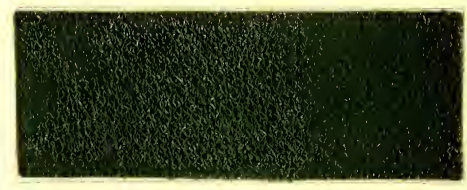

$14^{3 / 4} \mathrm{OZ}$ Cyanole F F

$61 / 4$, Indian Yellow $\mathrm{R}$ sulphuric acid.

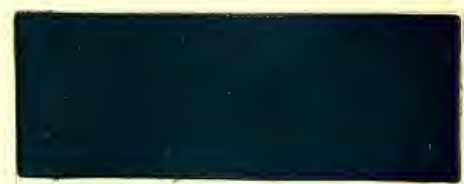

101/2 oz Solid Green Crystals O.

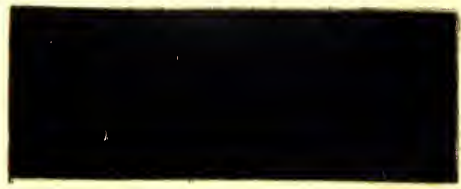

$156 *$

121/20\% l.eather Black TIB 13 pat. (i1/4 "Solid rireen Crystats (). 



\section{Skivers (Sheep).}

$157 \S$

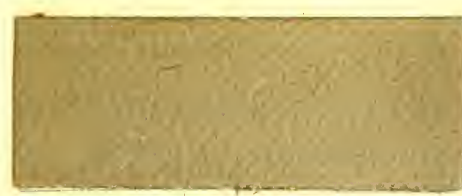

5 oz Neutral Black B for Leather

$6 \mathrm{dr}$ Havana Brown S conc. soap.

$159 \S$

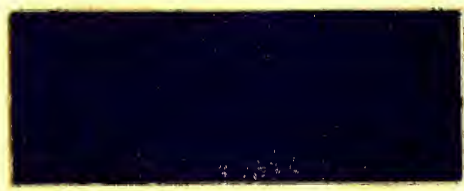

3 oz Water Blue R sulphuric acid.

$163 \dagger$

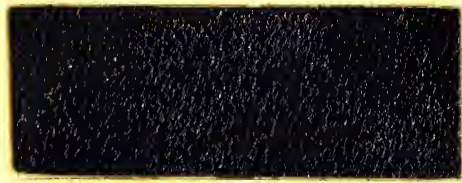

$210 z$ Solid Blue $6 \mathrm{G}$ sulphuric acid.

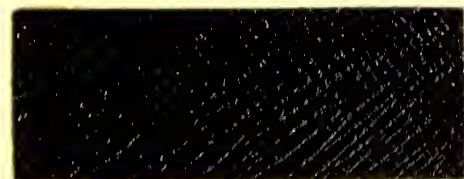

19) $0 \%$ Leather Black TI3 pat.

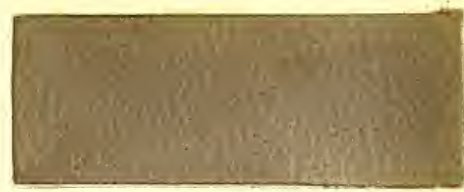

$10^{1 / 2}$ oz Neutral Black B for Leather soap.

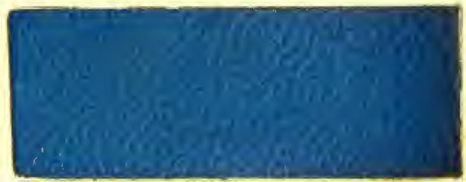

101/2 oz Cyanole FF sulphuric acid.

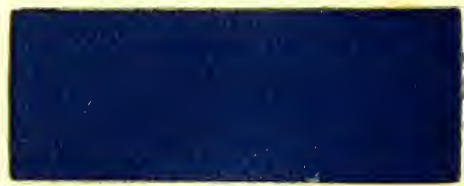

81/2 oz Methylene Blue D B B.

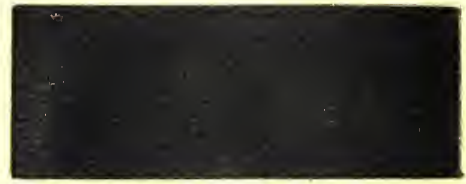

$21 / 2$ oz Nerazine G sulphuric acid.

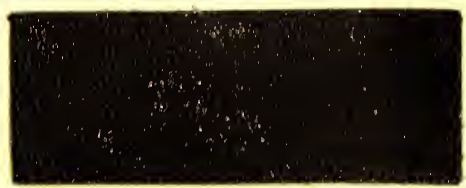

$190 \%$ Leather I3lack T(i pat.

The quantities of dyestuff for No 157 164 to be understood for 5 doz. skins, for No 165-166 for 10 gallons, to be applied by staining. 



\section{Chrome-tanned Calf Skins.}

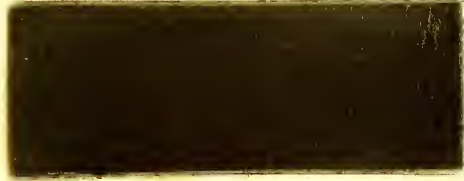

0,3 \% Neutral Black B for Leather $0,04 \%$ Havana Brown $\mathrm{S}$ cone.

Method I, page 17 .

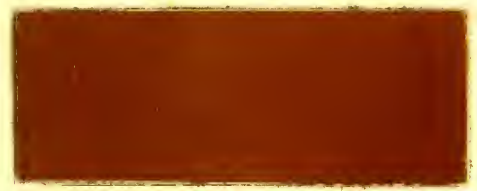

$1 \%$ Diamond Phosphine D

$0,04 \%$ Leather Brown A.

Iethod II, pages 18 and 19.

1,5 \% Fustic Extract

$0,1 \quad \%$ Logwood Extract

$0,4 \%$ Anthracene Yellow C Powder

$0,1 \%$ Anthracene Acid Brown B pat

$0,05 \%$ Bichromate of Potash

$0,2 \%$ Diamond Phosphine D. Method III, page 19

173

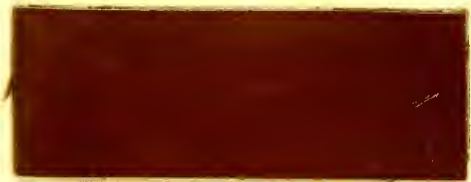

$1,2 \%$ Havana Brown $\mathrm{S}$ conc.

$0,2 \%$ Indian Yellow G

0,1 \% Naphtol Black B.

Method I, pages 16 and 17

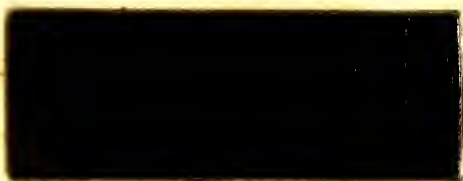

1,25\% Jeather Black J Eextra cone. pat $0,25 \%$ " Naphtylamine Blue Black 5 i $0,5 \%$ Logwood Extract.

$$
\text { Method IV a, page 210. }
$$

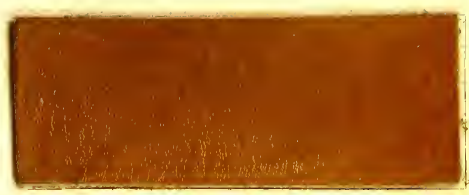

0,4 \% Diamond Phosphine GG

$0,6 \%$ Diamond Phosphine D

0,02\% New Blue D 120 .

Method II, pages 18 and 19

$2 \%$ Diamond Phosphine D

$0,06 \%$ Leather Brown A

0,$0 ; 0_{0}^{\circ}$ New Blue D 120.

Method II, pages 18 and 19

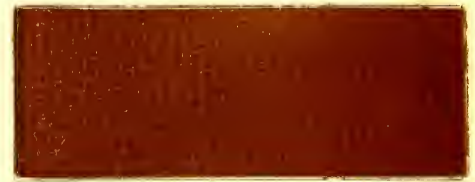

$1,5 \%$ Fustic Extract

$0,15 \%$ Logwood Extract

$0,4 \%$ Anthracene Yellow C Powde

$0,4 \%$ Anthracene Acid Brown B pat.

$0,04 \%$ Sulphate of Iron

$0,02 \%$ Sulphate of Copper

$0,2 \%$ Diamond Phosphine GG. Method III, page 19

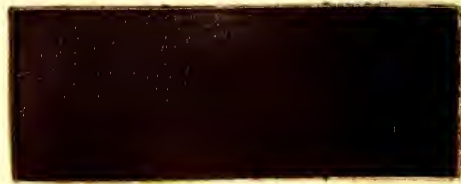

$1,2 \%$ Cerise $\mathrm{N}$

$0,3 \%$ Bismarek Brown FF G.

Method II, pages 18 and 19.

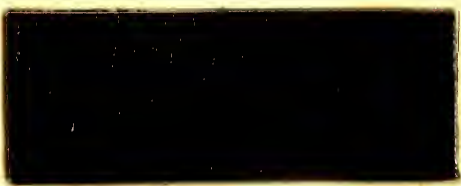

$0,5 \%$ Nerazine $\mathrm{G}$

$0,1 \quad 0 \%$ Formyl Violet 81

$0,50 \%$ Locrwood Extrac

topped whth

I It Eeather Black T B pat

per 10 gallons linuor.

vethed IV b, piage 21 

Chrome-tanned Goat Skins.

0,4 \% Havana Brown S conc. Method I, page 17.

179

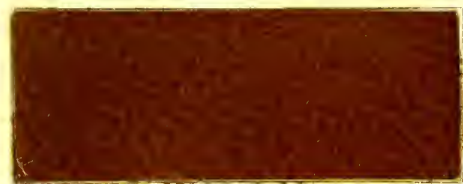

$0,8 \%$ Indian Yellow $\mathrm{G}$

$0,4 \%$ Havana Brown $\mathrm{S}$ cone.

$0,04 \%$ Naphtol Black B opped with

0,4 \% Diamond Phosphine G G. Method I, pages 16 and 17 .

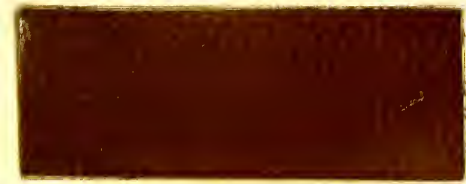

$0,5 \%$ Indian Yellow $\mathrm{G}$

$0,5 \%$ Havana Brown S conc.

$0,06 \%$ Naphtol Black B topped with

0,2\% Diamond Phosphine GG.

Method I, pages 16 and 17.

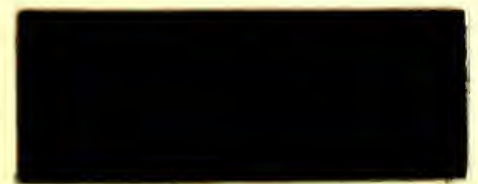

$1 \%$ Leather Black JF extra conc pat. 0,4 \% Logwood Extract.

Method IV, page 20.

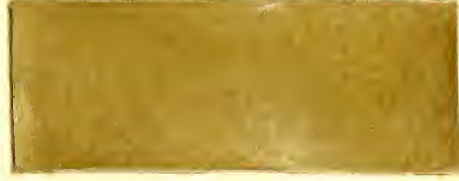

$0,3 \%$ Havana Brown $\mathrm{S}$ eone.

$0,05 \%$ Neutral Black B for Leather

Method I, page 17

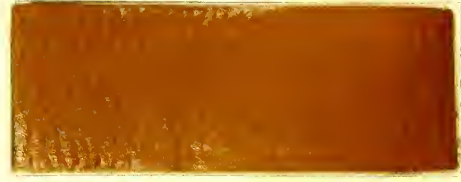

$0,8 \%$ Indian Yellow $\mathrm{G}$

0,2 \% Havana Brown $\mathrm{S}$ conc.

topped with

0,4\% Diamond Phosphine GG.

Method I, pages 16 and 17 .

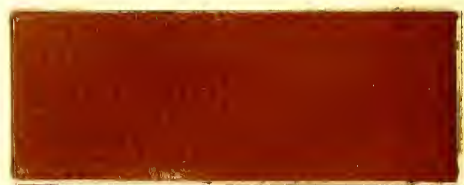

$2 \%$ Diamond Phosphine D.

Method II, pages 18 and 19.

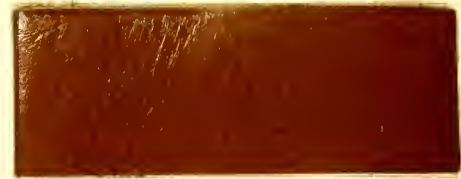

$1 \%$ Diamond Phosphine D $0,05 \%$ Bismarck Brown EE

$0,04^{\circ} \%$ New Blue D 120.

Nethod II, pages 18 and 19.

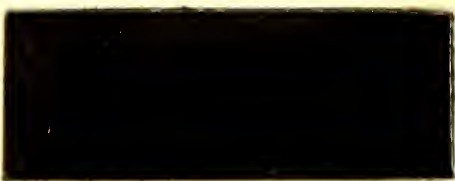

$1 \%$ Chrome leather Black 2061 il pat. $0,1 \quad \%$ Logwood Extract.

Melhod IV, page 90. 


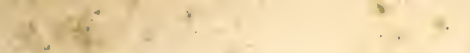

: 

(2)

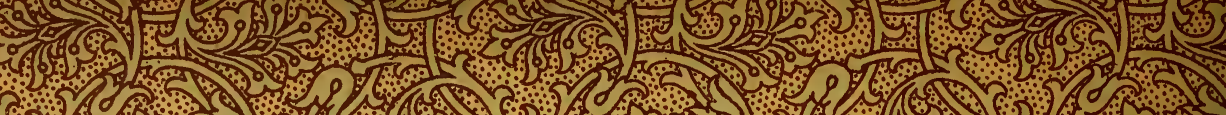

(3)

(6) (19)

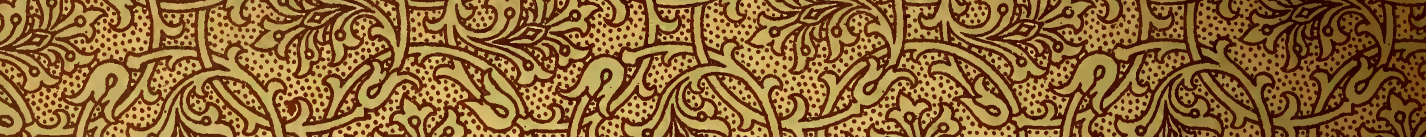
Q) 8 (3)

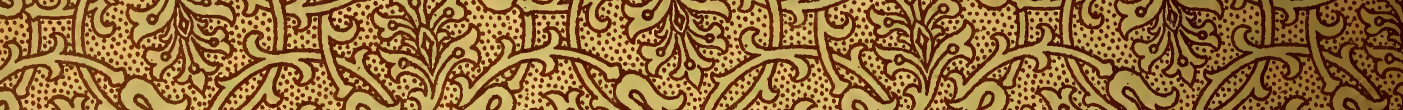
2) (0)

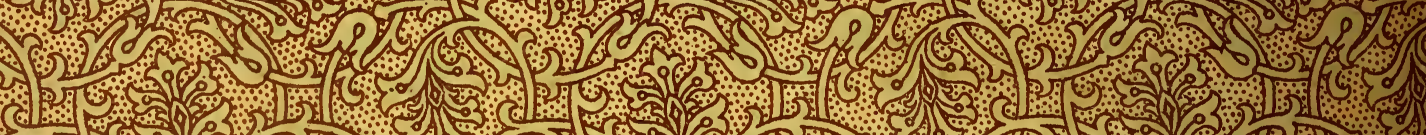

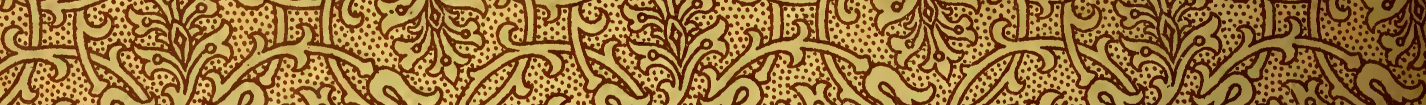

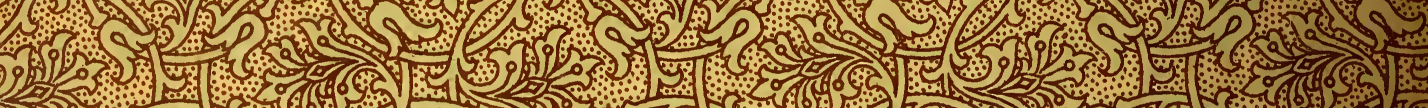
230 (1) 6)

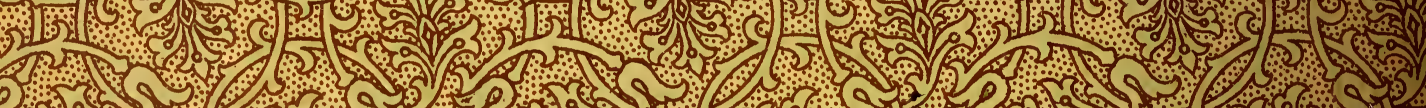
2) 1.5 2 (19) (c) 990 (3) a) D)

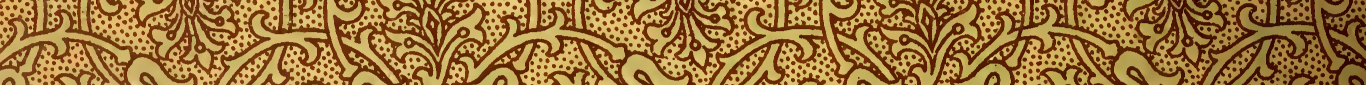
o) 1 (2)

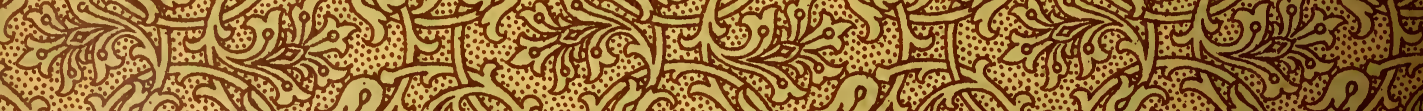

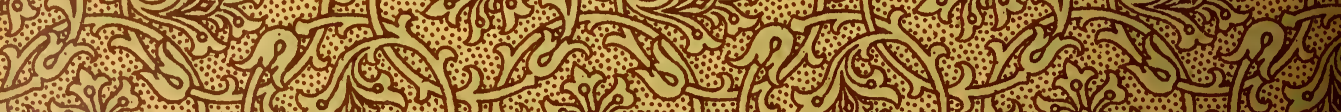
2.1.0. (1)

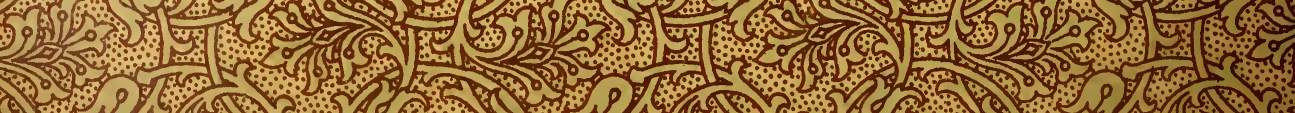

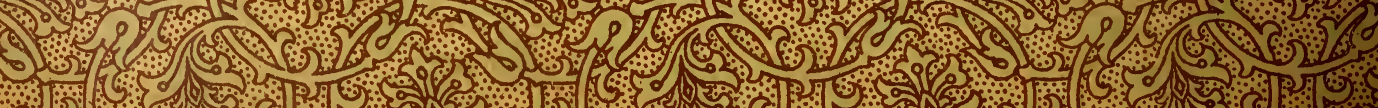

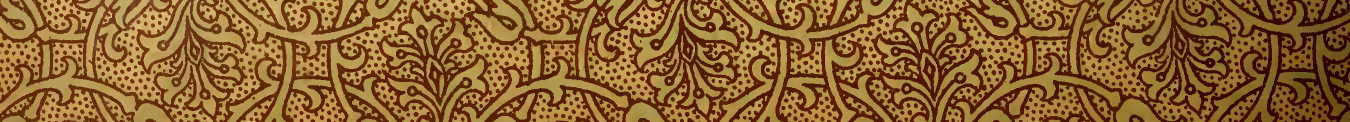




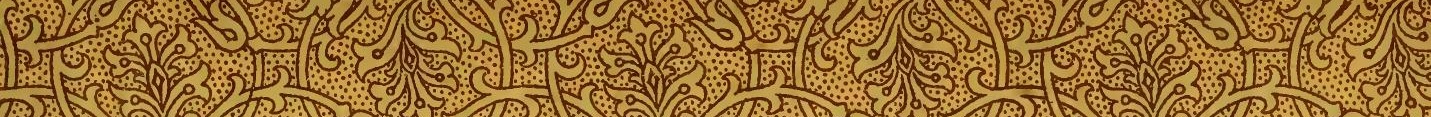

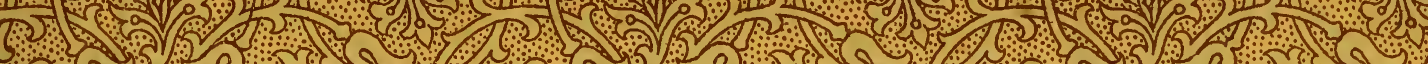

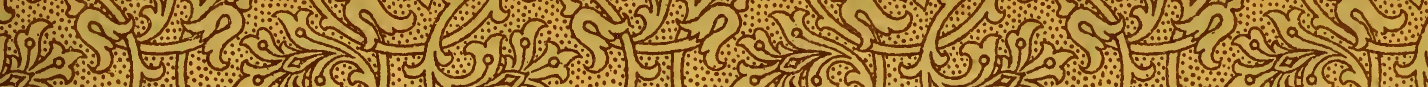

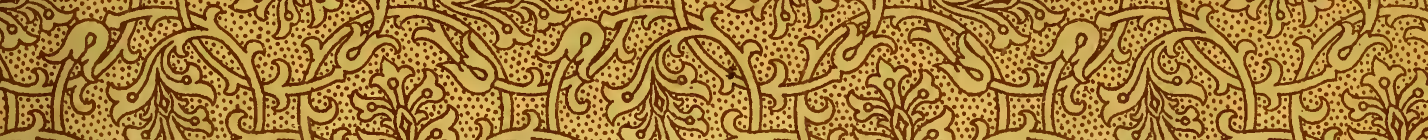

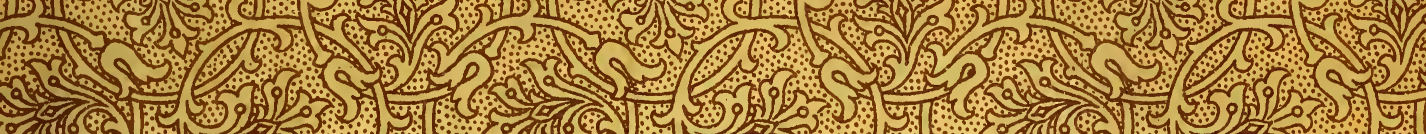
16.

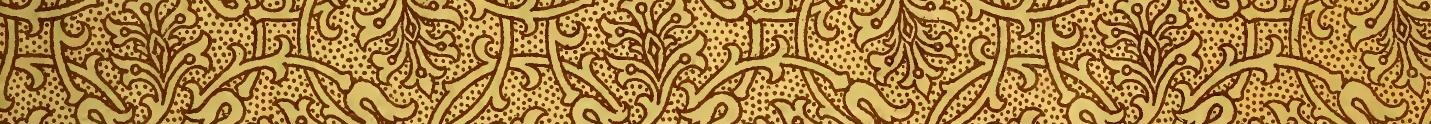

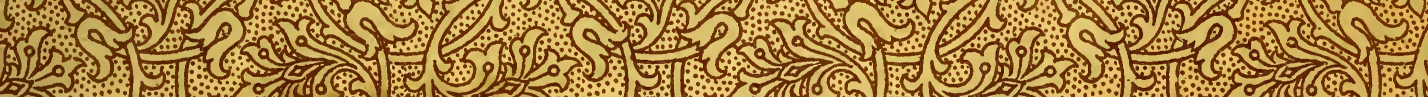

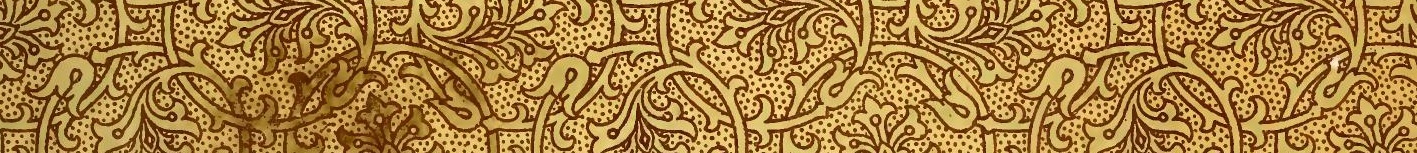

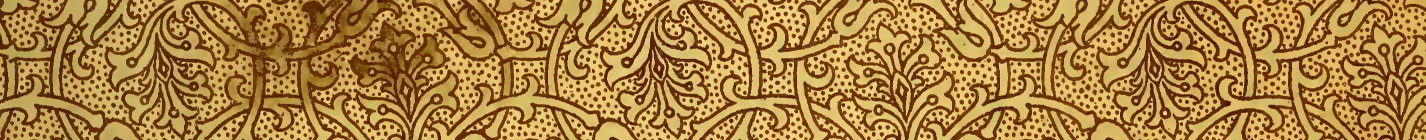
2014)

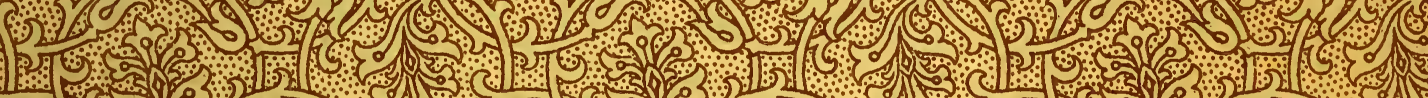
1) (5) 2(1) (1)

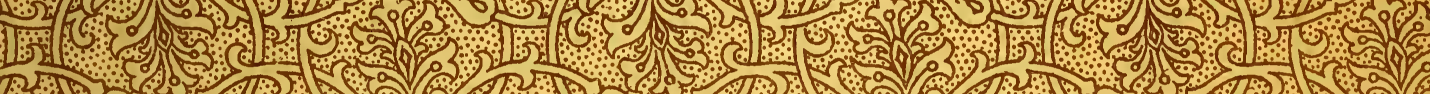

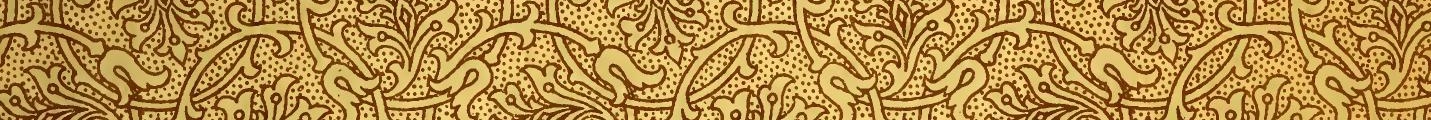

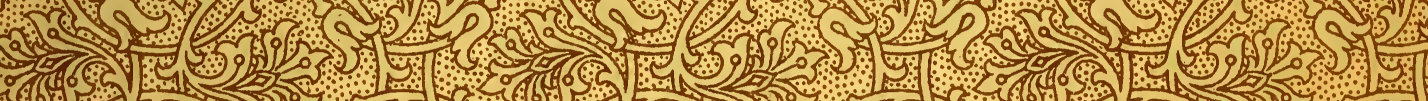
(5) 2 S153 6 (6)

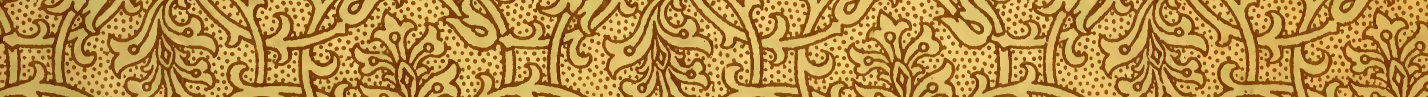
P a.t.

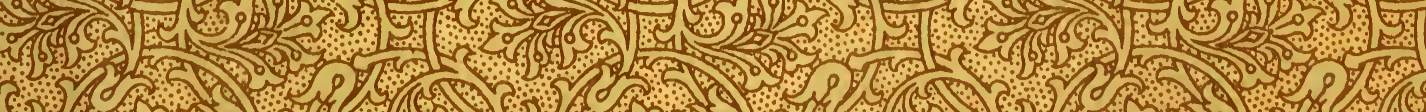

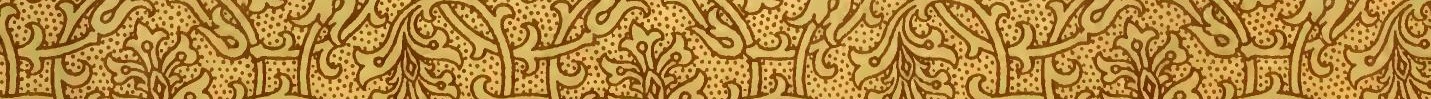

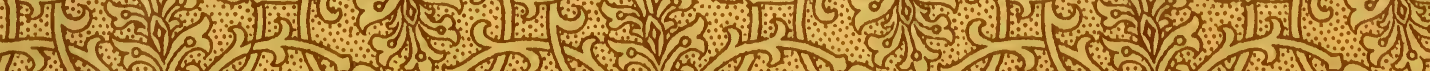

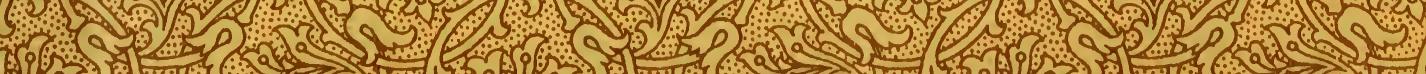

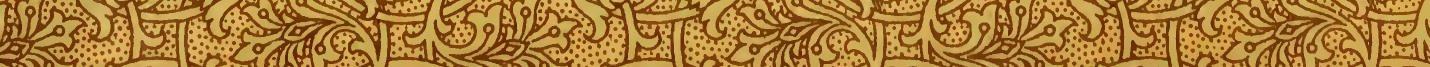

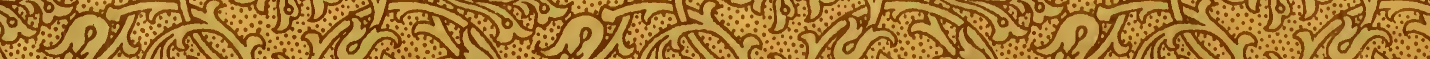


